\title{
Overview of the SMOS Sea Surface Salinity Prototype Processor
}

\author{
Sonia Zine, Jacqueline Boutin, Jordi Font, Nicolas Reul, Philippe Waldteufel, Carolina Gabarró, \\ Joseph Tenerelli, François Petitcolin, Jean-Luc Vergely, Marco Talone, and Steven Delwart
}

\begin{abstract}
The L-band interferometric radiometer onboard the Soil Moisture and Ocean Salinity mission will measure polarized brightness temperatures $(\mathrm{Tb})$. The measurements are affected by strong radiometric noise. However, during a satellite overpass, numerous measurements are acquired at various incidence angles at the same location on the Earth's surface. The sea surface salinity (SSS) retrieval algorithm implemented in the Level 2 Salinity Prototype Processor (L2SPP) is based on an iterative inversion method that minimizes the differences between $\mathrm{Tb}$ measured at different incidence angles and $\mathrm{Tb}$ simulated by a full forward model. The iterative method is initialized with a first-guess surface salinity that is iteratively modified until an optimal fit between the forward model and the measurements is obtained. The forward model takes into account atmospheric emission and absorption, ionospheric effects (Faraday rotation), scattering of celestial radiation by the rough ocean surface, and rough sea surface emission as approximated by one of three models. Potential degradation of the retrieval results is indicated through a flagging strategy. We present results of tests of the L2SPP involving horizontally uniform scenes with no disturbing factors (such as sun glint or land proximity) other than wind-induced surface roughness. Regardless of the roughness model used, the error on the retrieved SSS depends on the location within the swath and ranges from $0.5 \mathrm{psu}$ at the center of the swath to $1.7 \mathrm{psu}$ at the edge, at 35 psu and $15{ }^{\circ} \mathrm{C}$. Dual-polarization (DP) mode provides a better correction for wind-speed (WS) biases than pseudofirst Stokes mode (ST1). For a WS bias of $-1 \mathrm{~m} \cdot \mathrm{s}^{-1}$, the corresponding
\end{abstract}

Manuscript received April 13, 2007; revised November 30, 2007. The SMOS Level 2 Prototype Processor development was supported by the European Space Agency (ESA) under the ESTEC Contract 18933/05/NL/FF. Other contracts and projects supported by ESA are contributing to this development. This work was also supported in part by the "Terre, Océan, Surfaces Continentales, Atmosphère" Program of the Centre National d'Etudes Spatiales, and by the National Program on Space for the SMOS Barcelona Expert Center on Radiometric Calibration and Ocean Salinity, through Projects ESP2005-06823-C05 and ESP2007-65667-C04. M. Talone would like to thank the Spanish Ministry of Education and Science for the Formación de Personal Investigador fellowship.

S. Zine and J. Boutin are with the Institut Pierre-Simon Laplace, Laboratoire d'Océanographie et du Climat-Expérimentation et Approches Numériques (LOCEAN), Unité Mixte de Recherche Université Pierre et Marie CurieCentre National de la Recherche Scientifique-Institut de Recherche pour le Développement-Muséum National d'Histoire Naturelle, 75252 Paris, France (e-mail: zine@locean-ipsl.upmc.fr; jb@locean-ipsl.upmc.fr).

J. Font, C. Gabarró, and M. Talone are with the Institut de Ciències del Mar, Centre Mediterrani d'Investigacions Marines i Ambientals (CMIMA) Consejo Superior de Investigaciones Cientificas (CSIC), 08003 Barcelona, Spain.

N. Reul and J. Tenerelli are with the Institut Français de Recherche pour l'Exploitation de la Mer (IFREMER), 29280 Plouzané, France.

P. Waldteufel is with the Institut Pierre-Simon Laplace, Service d'Aéronomie du Centre National de la Recherche Scientifique, 91371 Verrières-le-Buisson, France.

F. Petitcolin and J.-L. Vergely are with ACRI-ST, 06904 Sophia Antipolis, France.

S. Delwart is with the European Space Research and Technology Centre (ESTEC), European Space Agency, 2200 AG Noordwijk, The Netherlands.

Digital Object Identifier 10.1109/TGRS.2008.915543
SSS bias at the center of the swath is equal to $-0.3 \mathrm{psu}$ in DP mode and to -0.5 psu in ST1 mode. The inversion methodology implicitly assumes that WS errors follow a Gaussian distribution, even though these errors should follow more closely a Rayleigh distribution. For this reason, the use of wind components, which typically exhibit Gaussian error distributions, may be preferred in the retrieval. However, the use of noisy wind components creates WS and SSS biases at low WSs $\left(0.1\right.$ psu at $\left.3 \mathrm{~m} \cdot \mathrm{s}^{-1}\right)$. At a sea surface temperature (SST) of $15{ }^{\circ} \mathrm{C}$, the retrieved SSS is weakly sensitive to the SST biases, with the SSS bias always lower than 0.3 psu for SST biases ranging from $-0.5{ }^{\circ} \mathrm{C}$ to $-2{ }^{\circ} \mathrm{C}$. In DP mode, biases in the vertical total electron content (TEC) of the atmosphere result in SSS biases smaller than $0.2 \mathrm{psu}$. The pseudofirst Stokes mode is insensitive to TEC. Failure to fully account for sea surface roughness scattering effects in the computation of sky radiation contribution leads to a maximum SSS bias of $0.2 \mathrm{psu}$ in the selected configuration, i.e., a descending orbit over the Northern Pacific in February. To achieve SSS biases that are smaller than $0.2 \mathrm{psu}$, special care must be taken to correct for biases at low WS and to ensure that the bias on the mean WS (averaged over $200 \mathrm{~km} \times 200 \mathrm{~km}$ and ten days) remains smaller than $0.5 \mathrm{~m} \cdot \mathrm{s}^{-1}$.

Index Terms-Microwave radiometry, oceanography, salinity.

\section{INTRODUCTION}

$\mathbf{S}$ OIL MOISTURE and sea surface salinity (SSS) are the key components of water cycle on Earth, and information on the distribution of these variables is the key to understanding the role of the water cycle in both the maintenance of the ocean circulation and the climate variability at various timescales. Although surface salinity and soil moisture are important components of atmospheric, oceanographic, and hydrologic forecasting models, it has not been possible to globally measure these variables with adequate resolution and coverage. In situ measurements remain scarce, and technological difficulties have inhibited the development of spaceborne observing systems.

The Soil Moisture and Ocean Salinity (SMOS) mission is one of the European Space Agency (ESA) Earth Explorer Opportunity Missions [1] within the ESA Living Planet Program. SMOS was proposed in 1998 by an international team of land and ocean scientists and engineers, and it is scheduled for launch in 2008. The SMOS instrument, MIRAS (Microwave Imaging Radiometer using Aperture Synthesis), uses aperture synthesis to obtain high spatial resolution over a large swath, which is similar to the way in which the Earth rotation synthesis in radio astronomy may be used to gain angular resolution. Since aperture synthesis instruments only require a thin array of small antennas rather than one large antenna, they have 
significant size and weight advantages over real aperture instruments, and these advantages are critical for space missions. The MIRAS L-band radiometer is dual polarized (with an optional fully polarimetric mode), and it has, by virtue of the aperture synthesis and wide field of view (FOV), a multiangular imaging capability [2], which may be exploited to reduce the impact of radiometric noise on salinity retrieval. This capability may also allow the retrieval of geophysical parameters [such as wind speed (WS)] other than the SSS. At L-band, the Stokes vector (with brightness temperatures collectively denoted by the symbol $\mathrm{Tb}$ ) of radiation emitted by the surface is sensitive to soil moisture [3] and SSS. In the case of ocean surface emission, these Tbs are a function of the dielectric constant of seawater. The dependence on salinity increases with decreasing frequency, and low microwave frequencies are required to detect changes in salinity with adequate sensitivity for the SSS retrieval. The spectral window at L-band reserved exclusively for passive use (1400-1427 MHz) provides sufficient sensitivity with modern radiometers for this purpose [4].

In addition to the low sensitivity of ocean surface Tbs to salinity at L-band [5], the following three major factors may hamper the retrieval of salinity with SMOS measurements:

1) limitations of the instrument (radiometric noise, calibration stability, and image reconstruction techniques);

2) limitations of the auxiliary information on the sea surface properties (temperature, roughness, etc.) and on external contributions (sky radiation, atmosphere, etc.);

3) limitations of the forward model components.

To reduce the impact of random errors, it will be necessary to spatially and temporally average the parameters obtained from SMOS retrievals (each of which is derived from measurements obtained from multiple views of a given area on Earth (i.e., a "footprint"), where each measurement corresponds to a footprint on the order of $40-50 \mathrm{~km}$ in diameter) in order to reduce the noise on the retrieved parameters [6], [7]. Several issues highly relevant for large-scale and climate studies can benefit from the SMOS observational approach: barrier layer effects on tropical Pacific heat flux, North Atlantic thermohaline circulation, surface freshwater flux balance, etc. The SMOS mission objective is to estimate the SSS with an accuracy of $0.1-0.2$ psu when retrievals are averaged over a 10-30-day period and over an open ocean area of $200 \times 200 \mathrm{~km}$ [8]. Such an accuracy is required in order to address the aforementioned issues [9].

The SMOS measurements are affected by strong radiometric noise. However, during a satellite overpass, numerous measurements are acquired at the same location on the Earth surface, resulting in nearly collocated (on Earth) measurements with incidence angles ranging from nadir to approximately $60^{\circ}$ (at the center of the swath). As part of the preparation of the Level 2 ground segment processing for the SMOS mission, we have developed a salinity retrieval algorithm based on an iterative inversion method that compares the Tbs reconstructed from the measured visibilities at different incidence angles with the Tbs simulated by a full forward model. This comparison is performed in the SMOS antenna polarization basis (i.e., in the "antenna reference frame"). The iterative method is initialized with a first-guess salinity that is modified until an optimal fit between the simulations and the measurements is obtained. The forward model takes into account atmospheric emission and absorption, scattering of celestial radiation by the rough ocean surface, Faraday rotation, and rough sea surface emission as approximated by one of three models. Potential degradation of the retrieval results is indicated through a flagging strategy. This algorithm is implemented in the Level 2 Salinity Prototype Processor (L2SPP).

In Section II, we present the philosophy, structure, and components of the SMOS salinity retrieval algorithm [10]. The forward model includes components that have been described previously in the literature as well as new components that have not. The former will be described briefly, and the latter will be described in more detail. Then, in Section III, we describe a series of idealized tests that has been performed in order to attempt to assess the expected performance of the algorithm. Key results from these tests are summarized and discussed in Section IV. Since surface wind, through its effect on surface roughness, is a key aspect of several components of the forward model, and since the wind may be represented as either speed and direction or as Cartesian components, in Appendix A, we relate the error characteristics of the WS to those of the wind components.

\section{DESCRIPTION OF THE SMOS L2SPP}

The SMOS L2SPP computes estimates of the SSS and geophysical parameters (sea surface temperature (SST), WS, or friction velocity, or other roughness descriptors, etc.) from Tbs provided by the SMOS Level 1C (L1C) after image reconstruction. Table I provides an overview of both levels 1 and 2 processing steps and output products. The L2SPP is the basis for the implementation of the Level 2 Operational Processor. With respect to earlier SMOS simulators (SMOS end-to-end performance simulator [11] and salinity retrieval software [12]), the L2SPP includes a more detailed formulation for reconstructed $\mathrm{Tb}$ noise and geometry as provided by the L1C Prototype Processor. Importantly, the L2SPP is capable of efficiently processing the SMOS L1C data in faster than real time; with three to five 64-bit Linux-based computers, each of which contains $4 \mathrm{~GB}$ of RAM, the processor is capable of processing $36 \mathrm{~h}$ of L1C data within $24 \mathrm{~h}$.

\section{A. SMOS Tb Characteristics}

The SMOS synthetic antenna consists of 69 antenna elements [Light Cost Effective Front-end antennas (LICEF)] distributed along three equally spaced arms, resulting in a planar Y-shaped structure. Discrete samples of the complex visibility functions are obtained from the cross correlations between simultaneous signals obtained from pairs of antenna elements. The image reconstruction process computes a $\mathrm{Tb}$ field consistent with this discrete visibility function. The Tb field and the visibility function are related by a discrete form of an integral relationship that is somewhat analogous to a Fourier transform [13]-[15]. The L1C product provides 2-D fields of $\mathrm{Tb}$ reconstructed in the antenna reference frame and corrected for the antenna pattern of the LICEF antennas. These Tbs are directly reconstructed onto an Earth-fixed grid known as the Icosahedral Snyder Equal 
TABLE I

OVERVIEW OF THE SMOS LEVELS 1 AND 2 PROCESSING CHAINS

\begin{tabular}{|c|c|c|}
\hline Level & Processing steps & Output product \\
\hline $\mathbf{1 A}$ & $\begin{array}{l}\text { - Extraction of calibration parameters and } \\
\text { offsets } \\
\text { - Calibration of instrument systems } \\
\text { - Transformation of raw data into calibrated } \\
\text { visibilities }\end{array}$ & Calibrated visibilities \\
\hline $1 B$ & $\begin{array}{l}\text { - Computation and calibration of system } \\
\text { response function (G matrix) } \\
\text { - Transformation of calibrated visibilities into } \\
\text { brightness temperatures (image } \\
\text { reconstruction) }\end{array}$ & $\begin{array}{l}\text { Brightness temperature Fourier } \\
\text { components }\end{array}$ \\
\hline $1 \mathrm{C}$ & $\begin{array}{l}\text { - Faraday angle computation } \\
\text { - Geolocation of brightness temperatures on } \\
\text { the ISEA grid }\end{array}$ & $\begin{array}{l}\text { Geolocated brightness temperatures } \\
\text { (antenna reference frame), incidence } \\
\text { and azimuth angles, radiometric } \\
\text { accuracy, Faraday and Claassen angles }\end{array}$ \\
\hline 2 & $\begin{array}{l}\text { - Measurement preprocessing } \\
\text { - Computation of contributions: } \\
\text { flat sea, sea surface roughness, sky radiation, } \\
\text { sun glint, atmospheric absorption and } \\
\text { emission, ionospheric effect } \\
\text { - Projection of modeled contributions into the } \\
\text { antenna reference frame } \\
\text { - Iterative retrieval of geophysical parameters }\end{array}$ & $\begin{array}{l}\text { Three sea surface salinities for each } \\
\text { node of the ISEA grid, with associated } \\
\text { uncertainties }\end{array}$ \\
\hline
\end{tabular}

Area (ISEA) grid [16]. At any point within the FOV, the Stokes vector in the instrument polarization basis is related to the Stokes vector in the surface basis by a linear transformation that is a function of the rotation angle between the two sets of basis vectors [17]. When the instrument is in full polarization mode, this linear transformation is invertible, and we may obtain the surface-basis Stokes vector from the Stokes vector in the antenna basis by inverting this relation. We compute the instrument basis Stokes components via the relation

$$
\begin{aligned}
{\left[\begin{array}{l}
A_{x} \\
A_{y} \\
A_{3} \\
A_{4}
\end{array}\right] } & =\left[\begin{array}{cccc}
\cos ^{2} \alpha & \sin ^{2} \alpha & -\cos \alpha \sin \alpha & 0 \\
\sin ^{2} \alpha & \cos ^{2} \alpha & \cos \alpha \sin \alpha & 0 \\
\sin (2 \alpha) & -\sin (2 \alpha) & \cos (2 \alpha) & 0 \\
0 & 0 & 0 & 1
\end{array}\right]\left[\begin{array}{l}
T_{\mathrm{h}} \\
T_{\mathrm{v}} \\
T_{3} \\
T_{4}
\end{array}\right] \\
& =(\operatorname{MR} 4)\left[\begin{array}{c}
T_{\mathrm{h}} \\
T_{\mathrm{v}} \\
T_{3} \\
T_{4}
\end{array}\right] .
\end{aligned}
$$

Here, the Stokes vector components $A_{x}$ and $A_{y}$ are in the instrument basis (and corrected for antenna pattern), $T_{\mathrm{h}}$ and $T_{\mathrm{v}}$ are the corresponding $\mathrm{Tb}$ horizontally and vertically polarized components in the Earth reference frame, and $\alpha=-\phi-\psi-\omega$ is the polarization basis rotation angle, where $\omega$ is the Faraday rotation angle [18], $\phi$ is azimuth in the antenna frame, and $\psi$ is a polarization basis rotation angle defined as in Claassen and Fung [19].

Every $1.2 \mathrm{~s}$ (in nominal operating mode), the sensor images a 2-D FOV called a "snapshot," for which the Tb for a given polarization is reconstructed from the visibilities at a range of incidence angles [20]. In dual-polarization (DP) mode, the Tbs in the two orthogonal polarizations are reconstructed from successive snapshots. Therefore, as the satellite progresses in its orbit, a given fixed point on Earth is observed several times at a set of locations within the FOV. This set of locations is referred to as a "dwell line," and it is nearly parallel to the subsatellite track in the instrument FOV. For each fixed point on Earth, a pair of consecutive reconstructed Tbs in orthogonal polarizations $A_{x}$ and $A_{y}$ is obtained. However, these two Tbs are reconstructed from visibilities acquired at slightly different times; thus, the incidence angles for these two Tbs differ by approximately $0.6^{\circ}$ in DP (corresponding to a satellite position shift of approximately $8 \mathrm{~km}$ at a height of $756 \mathrm{~km}$ ). This prevents an exact computation of the first Stokes parameter since (1) requires measurements obtained with the same geometry. Therefore, we introduce a "pseudofirst Stokes parameter." To build it, we sum a pair of consecutive measurements $A_{x}$ and $A_{y}$, which are obtained in the antenna reference frame at the incidence angles $\theta_{1}$ and $\theta_{2}$, for a specific grid point

$$
I\left(\theta_{1}, \theta_{2}\right)=A_{x}\left(\theta_{1}\right)+A_{y}\left(\theta_{2}\right) .
$$

The L2SPP can make use of either dual-polarized or fully polarized Tbs. The operating mode is not yet fixed and may change during the satellite lifetime. An option for using the pseudofirst Stokes parameter is under consideration since it minimizes the effects of Faraday rotation without significantly degrading the salinity retrieval [6], [21].

\section{B. Measurement Preprocessing}

The first step of the SMOS SSS retrieval algorithm is a selection of the subset of reconstructed Tbs that should be used in the retrieval process. At this stage, it is also determined if flags should be raised to indicate the possibility of errors in the retrieved salinity. The measurements are analyzed to discard suspect $\mathrm{Tbs}$ and to flag measurements that require specific processing. Specifically, the following tests are applied.

1) $\mathrm{Tb}$ range test. A first comparison is made between the measured and modeled Tbs. For this purpose, rough surface emissivity model 1 is used (see Section II-C). If the difference is above a threshold, the measurement is flagged and discarded.

2) Footprint size test. The spatial resolution (as determined by the elliptical footprint major axis length) of the measurement is checked. Only measurements with a major 
axis length less than $100 \mathrm{~km} \mathrm{[22]} \mathrm{are} \mathrm{used} \mathrm{in} \mathrm{the} \mathrm{retrieval.}$ All other measurements are flagged and discarded.

3) Grid-point position test. Grid points are classified by the L1C processor as belonging to the alias-free FOV (AF FOV), to the extended AF FOV (EAF FOV), or near the border between the aliased FOV and the AF FOV or the EAF FOV. The definition of the border zone is configurable. In a first approach, we consider $30 \mathrm{~km}$ inward. Grid points outside the EAF FOV are not processed, and border measurements are also rejected.

4) Ice presence test. When the SST is smaller than $2{ }^{\circ} \mathrm{C}$, a test is applied to measurements on grid points within the monthly climatological maximum extent of sea ice [23]. If the measured $\mathrm{Tb}$ exceeds that expected for a flat ocean surface by a critical threshold $\Delta A$ (with $\Delta A=20 \mathrm{~K}$ in a first approach), then the measurement is flagged to indicate that it is possibly contaminated by ice. If more than $50 \%$ of the measurements are flagged as potentially contaminated by sea ice, then the grid point is flagged as potentially ice contaminated, but salinity is retrieved nevertheless. If the ice concentration as indicated by external information [e.g., data supplied by the European Centre for Medium-Range Weather Forecasts (ECMWF)] is above $30 \%$, the grid point is flagged as ice contaminated, and the SSS retrieval is not performed.

5) Outlier test. The purpose of this test is to detect measurements that are likely to be erroneous because they deviate greatly from the forward-model Tb. For this purpose, the processor compares each measured $\mathrm{Tb}$ (denoted $A^{\text {meas}}$ ) to a modeled $\mathrm{Tb}$ (denoted $A$ mod $)$ in the antenna basis. If

$\left|\left(A^{\text {meas }}-A^{\text {mod }}\right)-\operatorname{median}\left(A^{\text {meas }}-A^{\text {mod }}\right)\right|>k \sigma_{A}$

then the measurement is flagged as an "outlier" and is not included in the retrieval. The median is computed using all Tbs measured at the same polarization for the grid point in question. $k$ is a factor that is nominally set equal to five, and $\sigma_{A}=\sqrt{\sigma_{A_{-} \text {meas }}^{2}+\sigma_{A_{-} \text {mod }}^{2}}$, where $\sigma_{A \_ \text {meas }}$ is the radiometric noise, and $\sigma_{A_{-} \bmod }$ is an estimate of the error on the model (in a first approach, we take $\sigma_{A_{-} \bmod }=\operatorname{Tb}_{\text {rough }}\left(\theta=0^{\circ}\right) / 2$, where $\mathrm{Tb}_{\text {rough }}$ is the contribution of sea surface roughness to the total $\mathrm{Tb}$, see Section II-C). The advantages of this method are threefold. The median is robust with a small number of measurements, the mean biases (model or instrument biases) are removed, and the corrections for atmosphere, celestial radiation, incidence angle variations, and Faraday rotation are taken into account. When the percentage of outliers detected for a grid point exceeds 50\%, the grid point is flagged as "possibly contaminated by radio-frequency interference (RFI), etc.," and the SSS retrieval is performed with the remaining $\mathrm{Tb}$. There is no means with which to discriminate between RFI and other disturbances that can produce these outliers.

6) Sun-contamination test. L1C will provide information on direct and reflected sun-contaminated measurements through various flags. At L2, a sun-glint model (see Section II-D2) will be applied, and measurements will be classified as no glint, low glint, medium glint, or high glint using three thresholds. The measurements flagged as possibly contaminated by sun glint by L1C will not be processed, and the measurements classified at Level 2 as sun-glint contaminated and with intensity above a threshold (that can coincide with the low, medium, or high threshold) will not be processed. When the percentage of the sun-contaminated measurements detected for a grid point exceeds $10 \%$, the grid point is flagged as possibly contaminated by sun glint, and the SSS retrieval is performed with the remaining $\mathrm{Tb}$.

7) Moon-glint test. The angle between target to moon direction and the measurement specular direction is checked. Measurements are flagged and not processed if the angle is smaller than $1.5^{\circ}$. When the percentage of the mooncontaminated measurements detected for a grid point is greater than $10 \%$, the grid point is flagged as possibly contaminated by the moon, and the SSS retrieval is performed with the remaining $\mathrm{Tb}$.

8) Sky radiation test. If the error on the sky radiation provided with the sky map [24] is larger than $0.1 \mathrm{~K}$, and the WS is below $2 \mathrm{~m} \cdot \mathrm{s}^{-1}$, then the measurement is flagged and not used in the retrieval. If the sky radiation is greater than $4 \mathrm{~K}$, then the measurement is flagged. When the percentage of the sky radiation-contaminated measurements detected for a grid point is greater than $10 \%$, the grid point is flagged as possibly contaminated by strong sky radiation, and the SSS retrieval is performed with the remaining $\mathrm{Tb}$.

9) Coastal zone test. Grid points are classified with respect to their distance to land. The SSS retrieval is not performed for grid points inside land or within $60 \mathrm{~km}$ of land. Retrieval is performed for grid points further than $60 \mathrm{~km}$ from land, but retrievals for grid points between 60 and $100 \mathrm{~km}$ from the coast are flagged to indicate that land may potentially impact the retrieval. The thresholds are taken from a previous study [22].

10) Heavy-rain test. If intense rainfall (more than $2 \mathrm{~mm} / \mathrm{h}$ ) is reported in at least one of four ECMWF cells around the retrieval grid point, the SSS is retrieved, but the retrieval is flagged as potentially affected by heavy rain.

All measurements that have successfully passed the tests are flagged as valid and used for the SSS retrieval. However, if the number of valid measurements for a given grid point is below 16, then the SSS retrieval is not performed.

Analysis of the flagging procedures will be subject to future investigations. The idealized tests described in Section III were performed, assuming that all available measurements are valid.

\section{Sea Surface Modeling}

At polarization $p$, the sea surface $\mathrm{Tb}$ can be expressed as follows:

$\operatorname{Tb}_{p}\left(\theta\right.$, SSS, SST, $\left.P_{\text {rough }}\right)=\operatorname{Tb}_{\text {flat }, p}(\theta$, SSS, SST $)$

$$
+\operatorname{Tb}_{\text {rough }, p}\left(\theta, \text { SSS, SST, } P_{\text {rough }}\right)
$$


where $\mathrm{Tb}_{\text {flat }}$ is the $\mathrm{Tb}$ of a flat sea surface, $\mathrm{Tb}_{\text {rough }}$ is the contribution of sea surface roughness, $\theta$ is the incidence angle, SST is the sea surface temperature, SSS is the sea surface salinity, and $P_{\text {rough }}$ is the parameter used to characterize the roughness. $\mathrm{Tb}_{\text {flat }, p}$ is given by

$$
\operatorname{Tb}_{\text {flat }, p}(\theta, \operatorname{SST}, \operatorname{SSS})=\left[1-R_{\text {flat }, p}(\theta, \varepsilon)\right] \operatorname{SST}
$$

where $R_{\text {flat }, p}$ is the Fresnel reflection coefficient at polarization $p$, and $\varepsilon$ is the dielectric constant of seawater. While a reasonably accurate model for the L-band emissivity of a flat sea exists [25], the models of L-band emission from a roughened surface are subject to large uncertainties in both the electromagnetic models and the surface description. A comparative analysis of the use of different rough surface emissivity models in salinity retrievals has shown that the forward model has a strong impact on the quality of the retrieved salinity and that the emissivity model errors can introduce biases in the results [26], [27]. Therefore, rough surface emissivity modeling is a key issue that deserves a significant validation and testing effort, and refinements in the models may be required after the SMOS launch in 2008. Three different roughness model options have been selected for implementation in the salinity retrieval algorithm, and they will be further evaluated during the calibration and validation $(\mathrm{Cal} / \mathrm{Val})$ phase. Two of them are theoretical models that require a statistical description of the sea surface and an asymptotic solution for rough surface electromagnetic scattering. Model 1 uses a two-scale approach to electromagnetic scattering and the Durden and Vesecky wave spectrum multiplied by two for the rough surface description [28]-[31]. It is currently the default model in the L2SPP. Model 2 uses the small slope approximation emission theory [32], [33] and the Kudryavtsev sea surface wave spectrum model [34]. This model partitions the ocean surface into foamfree and foam-covered areas, and it includes a specific foam emissivity model to account for the effect of the presence of foam on the sea surface emission [35]. Foam contribution can have a significant impact for the WSs in excess of $10-12 \mathrm{~m} \cdot \mathrm{s}^{-1}$ [36]. Models 1 and 2 have been compared with the experimental data with good results [10], [37]. Model 3 is a semiempirical formulation derived from the few existing data sets provided by campaigns in the Mediterranean Sea that have measured the L-band-polarized emission of the sea surface together with oceanographic and meteorological parameters recorded in coincidence with the radiometric data [38], [39]. Model 3 has been used to retrieve the salinity from airborne radiometric measurements acquired in a region characterized by a large range of oceanographic conditions. The results show that the model performs fairly well [40]. Model 3 has multiple possible configurations which may be selected by varying a set of input parameters, and these configurations will be tested and tuned during the SMOS Cal/Val phase.

To compute the roughness contribution, model 1 uses the 10-m neutral equivalent WS, model 2 uses the friction velocity $u^{*}$, and model 3 , in its default configuration, uses the $10-\mathrm{m}$ neutral equivalent WS and the significant wave height $H_{\mathrm{s}}$. In order to compare the roughness contributions given by the three models, we implicitly assume that several conditions apply.

1) The sea is fully developed.

2) The relationship between $u^{*}$ and WS is given by $\left(u^{*} / \mathrm{WS}\right)=\sqrt{C_{\mathrm{D}}}$, where the drag coefficient $C_{\mathrm{D}}$ is taken as equal to $1.3 \times 10^{-3}$

3) The relationship between $H_{\mathrm{s}}$ and WS is given by the wave analysis model [41], with $H_{\mathrm{s}}=1.614 \times 10^{-2} \times$ $\mathrm{WS}^{2}$ if $\mathrm{WS} \leq 7.5 \mathrm{~m} \cdot \mathrm{s}^{-1}$ and $H_{\mathrm{s}}=10^{-2} \times \mathrm{WS}^{2}+$ $8.134 \times 10^{-4} \times \mathrm{WS}^{3}$ if WS $>7.5 \mathrm{~m} \cdot \mathrm{s}^{-1}$.

With these assumptions, the variation with incidence angle of Tb excess owing to the rough surface emission, as computed using three roughness models for three WSs, is shown in Fig. 1(a) and (b).

At $6 \mathrm{~m} \cdot \mathrm{s}^{-1}$, both models 1 and 2 give similar results in both linear polarizations for incidences less than $50^{\circ}$. At $16 \mathrm{~m} \cdot \mathrm{s}^{-1}$, their simulated WS dependences follow similar trends up to about $50^{\circ}$ in horizontal polarization and $40^{\circ}$ in vertical polarization, where different dependences are observed. At large incidence angles, the differences can be explained by the combined contributions from either of the following: 1) the foam impact, which is accounted for in model 2 but not in model $1 ; 2$ ) the differing sea surface slope statistics (meansquare slopes) between the rough surface models (specifically, the surface spectral model used in model 1 implies a meansquare slope twice those reported in Cox and Munk's laws [42], whereas model 2 is constrained to obey these laws); and 3 ) the impact of tilting larger waves in model 1 that are not contributing in model 2 . In all cases, model $3 \mathrm{~Tb}$ excess varies linearly with the incidence angle.

The dependence of rough surface Tb excess on surface WS, as computed using the three roughness models, is shown in Fig. 1(c) and (d) for various incidence angles. For WSs higher than $3 \mathrm{~m} \cdot \mathrm{s}^{-1}$, both models 1 and 3 exhibit nearly linear dependence with WS (except at $60^{\circ}$ in the vertical polarization for model 1), whereas model 2 exhibits a strong nonlinear dependence. This departure of the behavior of model 2 may be attributed to the impact of foam, which becomes significant for WSs larger than $10 \mathrm{~m} \cdot \mathrm{s}^{-1}$.

\section{Contributions From Other Sources}

1) Sky Radiation: Estimation of the downwelling celestial sky radiation at L-band that is scattered by the sea surface and sensed by Earth-viewing radiometers (sky glitter) is of particular concern for the remote sensing of SSS [5], [43], [44]. At L-band, this radiation originates from the uniform cosmic microwave background (about $2.7 \mathrm{~K}$ ), the line emission from hydrogen, and a continuum background [44], [45]. Sea surface scattered sky radiation might hamper the accurate SSS retrievals from spaceborne measurements of upwelling sea surface Tbs at L-band, as the sky-glitter contribution is expected to vary from roughly $2 \mathrm{~K}$ to more than $7 \mathrm{~K}$, which is significant with respect to the SSS signature. Sky-glitter contamination is expected to be geographically and seasonally variable. Correction strategies for this contamination are therefore needed to be able to retrieve unbiased large-scale seasonal and geographical features of the global SSS field. The L2SPP will apply a 


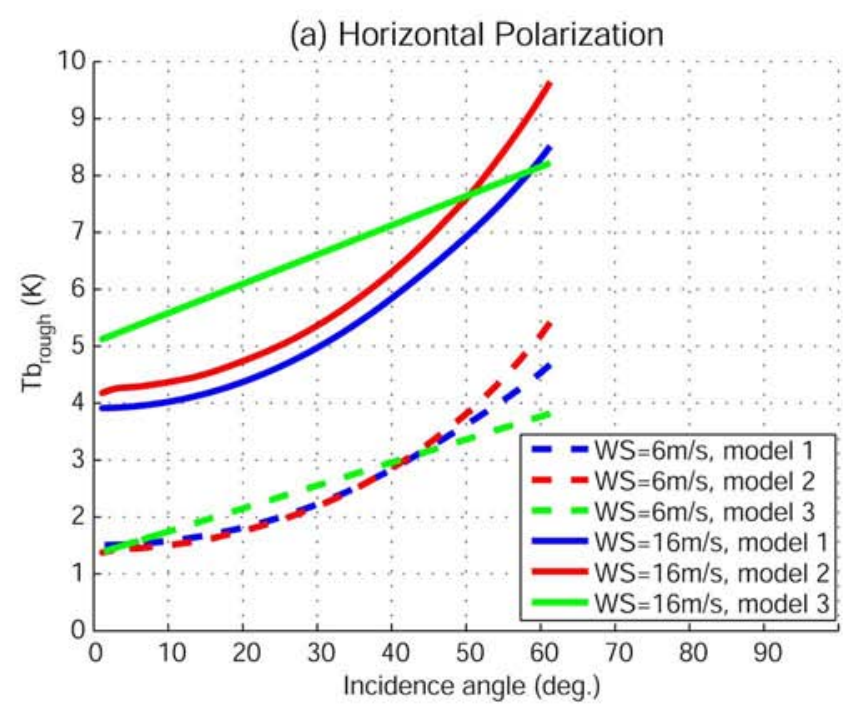

(c) Horizontal Polarization

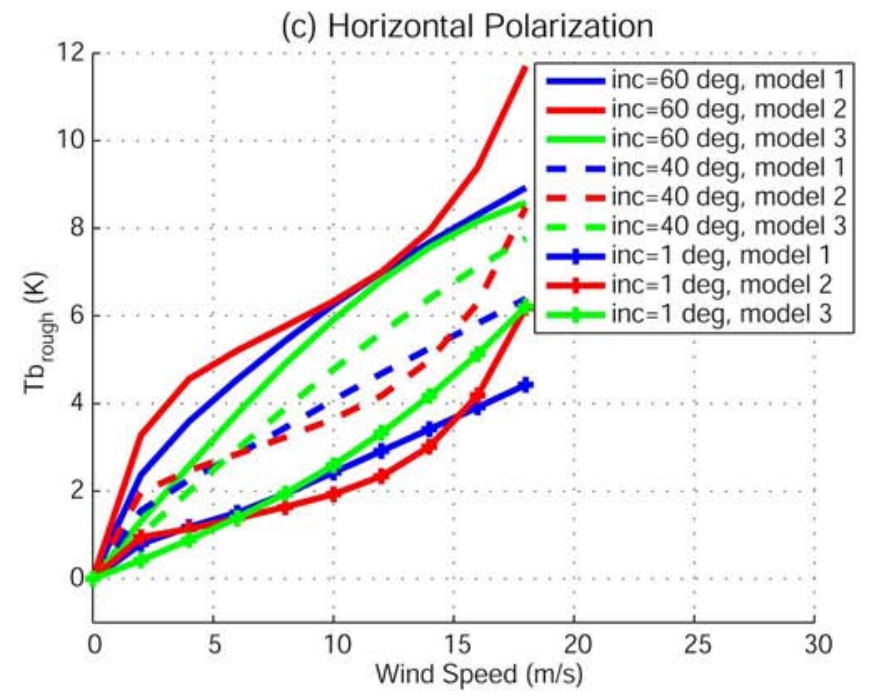

(b) Vertical Polarization

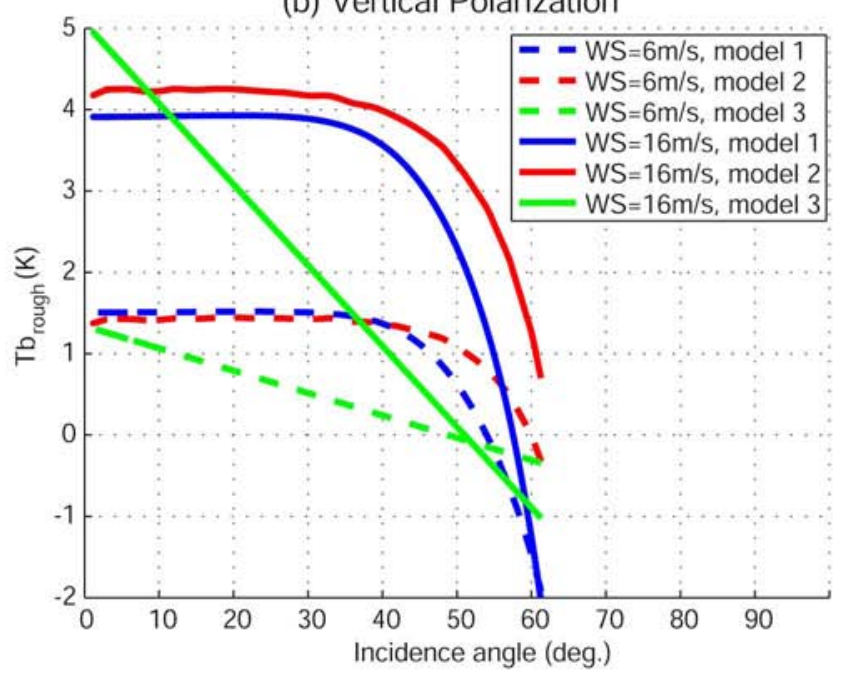

(d) Vertical Polarization

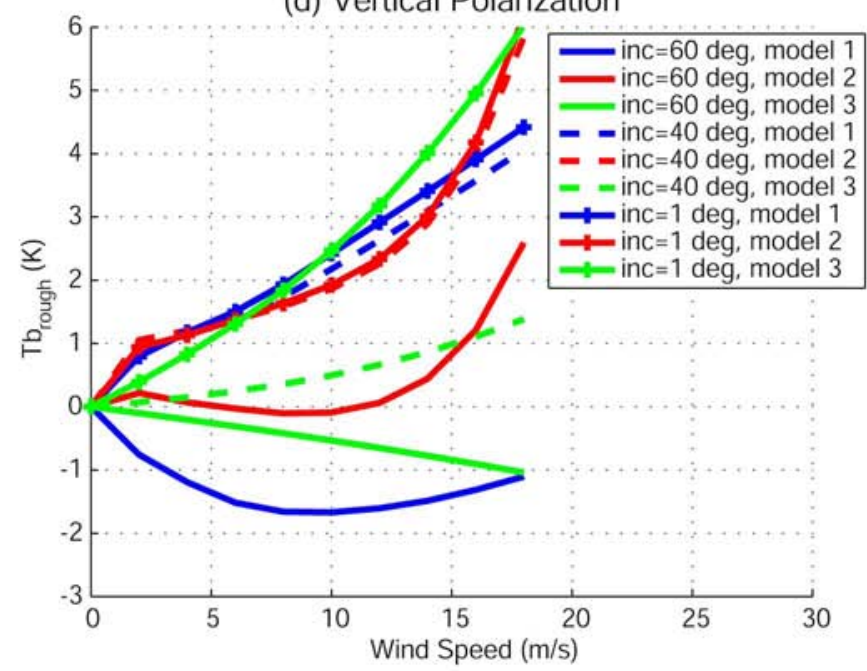

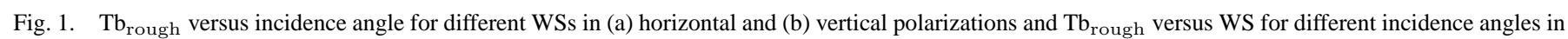

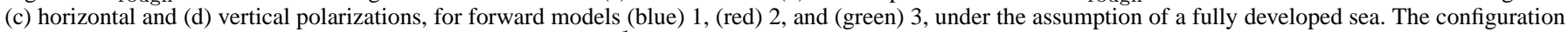
selected here for model 3 is only valid between 3 and $12 \mathrm{~m} \cdot \mathrm{s}^{-1}$.

correction, taking into account the rough sea surface scattering effect [24], [46]. The influence of this correction on the retrieved salinity is studied in Section III-C.

2) Sun Glint: The sun is an extremely strong radiation source at L-band, exhibiting a time-dependent blackbody temperature that ranges between $10^{5}$ and $10^{7} \mathrm{~K}$, depending on solar activity [47]. Two distinct mechanisms may contribute to the solar radiation intercepted by a radiometer antenna. One is the reflection of sun radiation by the Earth surface (sunglitter effects), and the other is the direct leakage into the antenna. The direct and reflected sun effects in a 2-D aperture synthesis radiometry imaging with SMOS have been studied, and cancellation techniques to remove these effects during the image reconstruction process have been discussed and proposed in [48]-[50]. These signals affect the average Tb of the Earth, which translates into a reconstructed image bias. To remove these biases at Level 1, visibility samples that would be measured by the instrument corresponding to point source located at the positions of the direct sun are computed and subtracted from the measured visibilities prior to the reconstruction process. While the shape of the direct sun image is not perturbed, the reflected sun image will be distorted by the rough Earth surface. Simulations of the sun-glint-induced image reconstruction biases based on forward scattering models revealed that these biases are very weakly WS dependent [50]. Therefore, a uniform $7-\mathrm{m} / \mathrm{s}$ WS is assumed over the oceans to evaluate the sun-glint-induced image reconstruction biases at Level 1 . At Level 2, the sun-glint contamination is evaluated based on models and geophysical parameters in order to eventually flag the measurements. The center of the sun's glitter pattern will never be located in the SMOS AF FOV [49]. However, the expected range of surface WSs will cause the sun's glitter pattern to spread within the AF FOV, and this might contaminate the useful measured signal. More specifically, frequent contaminations are expected near the winter solstices when the center of the sun's glitter pattern will lie close to the right-hand 


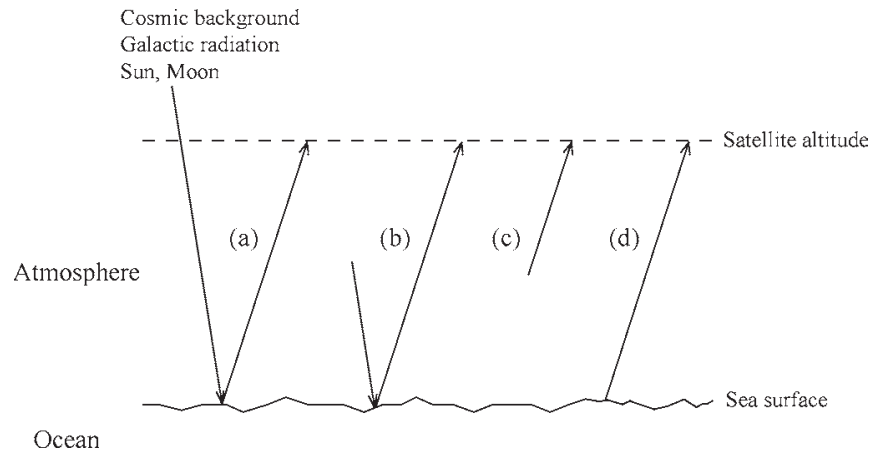

Fig. 2. Radiative contributions to the SMOS signal. (a) Extraterrestrial radiation and (b) downward atmospheric emission reflected on the sea surface toward the instrument. (c) Upward atmospheric emission and (d) sea surface emission toward the instrument. Each contribution is attenuated by absorption in the atmosphere, and atmospheric scattering is assumed to be negligible at L-band.

border of the FOV. These sun-glitter effects are modeled using the Kirchhoff asymptotic scattering theory to compute the forward scattering of the sun radiations from the rough water surface [51]. Since we expect the fraction of affected measurements to be small, such measurements will be flagged and discarded, and no correction will be applied.

3) Atmospheric Effects:

a) Atmospheric absorption and emission: Several constituents of the atmosphere are radiatively important at L-band, so that atmospheric self-emission and attenuation must be accounted for by the following:

$$
\mathrm{Tb}_{\mathrm{TOA}}=\mathrm{Tb}_{\mathrm{s}} \exp \left(-\tau_{\mathrm{atm}}\right)+\mathrm{Tb}_{\mathrm{up}}+\Gamma \mathrm{Tb}_{\mathrm{down}} \exp \left(-\tau_{\mathrm{atm}}\right)
$$

where $\mathrm{Tb}_{\mathrm{TOA}}$ is the $\mathrm{Tb}$ at the top of the atmosphere, $\mathrm{Tb}_{\mathrm{s}}$ is the upwelling $\mathrm{Tb}$ from the surface, $\mathrm{Tb}_{\mathrm{up}}$ is the Tb self-emitted by the atmosphere upward and attenuated along the upward path, and $\mathrm{Tb}_{\text {down }}$ is the $\mathrm{Tb}$ self-emitted by the atmosphere downward and attenuated along the downward path (Fig. 2). $\mathrm{Tb}_{\text {up }}$ and $\mathrm{Tb}_{\text {down }}$ are usually derived using a multilayer model. In the following, we will show that, at L-band, a simplified model can be used. $\tau_{\text {atm }}$ is the equivalent optical thickness of the atmosphere, and $\Gamma$ is the surface reflection coefficient, with $\Gamma=1-e$. The emissivity $e$ is computed for a rough surface: $e=\left(\mathrm{Tb}_{\text {flat }}+\mathrm{Tb}_{\text {rough }} /(\mathrm{SST})\right)$.

There are four atmospheric constituents to be considered: dry atmosphere, water vapor, clouds, and rain. Ideally, each of the quantities identified in (6), i.e., $\tau_{\mathrm{atm}}, \mathrm{Tb}_{\mathrm{up}}$, and $\mathrm{Tb}_{\text {down }}$, is the sum of the four corresponding contributions.

The radiatively active component in the dry atmosphere is molecular oxygen. Oxygen molecules have a permanent magnetic moment; therefore, absorption and radiation in the microwave region occur due to magnetic interactions with the incident field. This interaction produces a family of rotation absorption lines in the vicinity of $60 \mathrm{GHz}$ (known as the oxygen complex) and an additional isolated line at $118.8 \mathrm{GHz}$ [52]. In the lower part of the Earth's atmosphere, pressure broadening causes the complex of lines to blend together to a continuous absorption band centered around $60 \mathrm{GHz}$. The absorptivity and the emissivity of molecular oxygen at L-band depend on the pressure $P(z)$ and the temperature $T(z)$ of the atmosphere as a function of the altitude $z$. A model for the absorption by oxygen at lower microwave frequencies is described in [53]. For frequencies below $45 \mathrm{GHz}$, the contribution from the $118.75-\mathrm{GHz}$ oxygen absorption line can be neglected, leaving only the contribution from the $60-\mathrm{GHz}$ absorption line. The oxygen contribution is, by far, the largest atmospheric contribution [54].

In the microwave region, water vapor has rotational absorption lines at 22.235 and $183.31 \mathrm{GHz}$. Furthermore, there are also some absorption lines above this region, which contribute to the microwave absorption spectrum. For calculation of the absorption at L-band, one can, according to Ulaby et al. [53], group the contributions from the $183.31 \mathrm{GHz}$ and all the absorption lines above in a residual term through the use of a low-frequency approximation.

Radiative effects of ice clouds are negligible at L-band. Concerning liquid water clouds, according to Ulaby et al. [53] and Peichl et al. [54], empirical expressions have been developed by Benoit [55] for the absorption coefficient. It appears that the only cases where the overall radiative effect at L-band might not be negligible originate from deep cumulus clouds. However, there is no reliable auxiliary data on the depths of these clouds. Moreover, they are mostly associated with rain events, which are considered next.

According to Peichl et al. [54], rain in the atmosphere produces a nonnegligible radiative contribution when the rain intensity exceeds about $10 \mathrm{~mm} / \mathrm{h}$ (at the SMOS footprint scale); this is estimated to occur less than $0.2 \%$ of the time over all latitudes and less than $0.65 \%$ of the time over equatorial areas (these figures may be pessimistic at 6 A.M. local time). Given the lack of available rain-rate information on a global scale, potentially rain-contaminated retrievals are flagged with no attempt at correction (see Section II-B). As previously stated, the heavy clouds should be associated with rain events. However, there are obviously cases for which rain attenuation effects will be significant. This deserves further study, including an attempt to build a forward model for the rain contribution.

Numerical simulations using the Liebe model [56] show that, at L-band, the $\mathrm{Tb}_{\mathrm{up}}$ and $\mathrm{Tb}_{\text {down }}$ radiative contributions differ from less than $0.01 \mathrm{~K}$ because the main contribution to both of these Tbs is emission from a thin layer near the surface. Consequently, they can be assumed equal to a single value $\mathrm{Tb}_{\mathrm{atm}}$ in (6).

With the preceding considerations, the atmospheric contribution to the Tb incident at the satellite may be computed with the following information:

$$
\begin{gathered}
\tau_{\text {atm }}=\tau_{\mathrm{O}_{2}}+\tau_{\mathrm{H}_{2} \mathrm{O}} \\
\mathrm{Tb}_{\mathrm{atm}}=\mathrm{Tb}_{\mathrm{O}_{2}}+\mathrm{Tb}_{\mathrm{H}_{2} \mathrm{O}} .
\end{gathered}
$$

For the purpose of SMOS data inversion, a multilayer model is not necessary to simulate the atmospheric effects at L-band, and we propose regressions to easily compute $\tau_{\text {atm }}$ and $\mathrm{Tb}_{\mathrm{atm}}$. The emission of each component is written as the product of optical thickness $\tau$ and an equivalent layer (physical) 
TABLE II

Coefficients of the Simplified Atmosphere Model

\begin{tabular}{ccc}
\hline Coefficient & Value & Units \\
\hline $\mathrm{a}_{0}$ & $8.03325 \times 10^{3}$ & neper \\
\hline $\mathrm{a}_{1}$ & $-1.03999 \times 10^{2}$ & neper $\cdot \mathrm{K}^{-1}$ \\
\hline $\mathrm{a}_{2}$ & $2.82992 \times 10$ & neper $\cdot \mathrm{hPa}^{-1}$ \\
\hline $\mathrm{a}_{3}$ & $2.62584 \times 10^{-1}$ & neper $\cdot \mathrm{K}^{-2}$ \\
\hline $\mathrm{a}_{4}$ & $6.43081 \times 10^{-3}$ & neper $\cdot \mathrm{hPa}^{-2}$ \\
\hline $\mathrm{a}_{5}$ & $-9.42431 \times 10^{-2}$ & neper $\cdot \mathrm{K}^{-1} \cdot \mathrm{hPa}^{-1}$ \\
\hline $\mathrm{b}_{0}$ & $-7.78882 \times 10^{-1}$ & $\mathrm{~K}$ \\
\hline $\mathrm{b}_{1}$ & $1.37576 \times 10^{-1}$ & dimensionless \\
\hline $\mathrm{b}_{2}$ & $-1.14919 \times 10^{-3}$ & $\mathrm{~K} \cdot \mathrm{hPa}$ \\
\hline $\mathrm{b}_{3}$ & $-1.15781 \times 10^{-4}$ & $\mathrm{~K} \cdot \mathrm{hPa}^{-2}$ \\
\hline $\mathrm{b}_{4}$ & $1.28474 \times 10^{-6}$ & $\mathrm{hPa}$ \\
\hline $\mathrm{b}_{5}$ & $-1.11330 \times 10^{-5}$ & $\mathrm{neper}$ \\
\hline $\mathrm{c}_{0}$ & $-1.47866 \times 10^{2}$ & $\mathrm{neper} \cdot \mathrm{hPa}$ \\
\hline $\mathrm{c}_{1}$ & $1.50999 \times 10^{-1}$ & $\mathrm{neper} \cdot \mathrm{m}^{2} \cdot \mathrm{kg}^{-1}$ \\
\hline $\mathrm{c}_{2}$ & 3.75477 & $\mathrm{~K}$ \\
\hline $\mathrm{d}_{0}$ & 8.18092 & $\mathrm{~K} \cdot \mathrm{hPa}^{-1}$ \\
\hline $\mathrm{d}_{1}$ & $2.79377 \times 10^{-4}$ & $\mathrm{~K} \cdot \mathrm{m}^{2} \cdot \mathrm{kg}^{-1}$ \\
\hline $\mathrm{d}_{2}$ & $3.72190 \times 10^{-2}$ &
\end{tabular}

temperature, which is defined by its difference $\Delta T$ with the surface air temperature $T_{0}$

$$
\mathrm{Tb}_{x}=\left(T_{0}-\Delta T_{x}\right) \tau_{x}
$$

where $x$ identifies the component (oxygen or water vapor) considered.

For dry atmosphere, a quadratic fit to the results obtained using the multilayer model has been found necessary

$$
\tau_{\mathrm{O}_{2}}=\frac{a_{0}+a_{1} T_{0}+a_{2} P_{0}+a_{3} T_{0}^{2}+a_{4} P_{0}^{2}+a_{5} T_{0} P_{0}}{\cos \theta} 10^{-6}
$$$$
\Delta T_{\mathrm{O}_{2}}=b_{0}+b_{1} T_{0}+b_{2} P_{0}+b_{3} T_{0}^{2}+b_{4} P_{0}^{2}+b_{5} T_{0} P_{0}
$$

where $\theta$ is the incidence angle, and $P_{0}$ is the surface pressure.

For the water vapor contribution, a linear fit is found adequate

$$
\begin{aligned}
\tau_{\mathrm{H}_{2} \mathrm{O}} & =\max \left(\frac{c_{0}+c_{1} P_{0}+c_{2} \mathrm{WVC}}{\cos \theta} 10^{-6}, 0\right) \\
\Delta T_{\mathrm{H}_{2} \mathrm{O}} & =d_{0}+d_{1} P_{0}+d_{2} \mathrm{WVC}
\end{aligned}
$$

where WVC is the total precipitable water-vapor content. Coefficient values are detailed in Table II. The difference between $\mathrm{Tb}_{\mathrm{TOA}}$ (6) simulated with the simplified atmosphere model and $\mathrm{Tb}_{\mathrm{TOA}}$ simulated with the multilayer model is less than $0.05 \mathrm{~K}$ at low incidence angles and less than $0.1 \mathrm{~K}$ at $50^{\circ}$ (Fig. 3). With the simplified atmosphere model and for a flat sea, the total atmospheric contribution (i.e., $\mathrm{Tb}_{\mathrm{TOA}}-\mathrm{Tb}_{\mathrm{s}}$ ) ranges from $2.6 \mathrm{~K}$ at nadir to $3.4 \mathrm{~K}$ in vertical polarization and $5.6 \mathrm{~K}$ in horizontal polarization at $56^{\circ}$ of incidence angle.

b) Faraday rotation: Another atmospheric effect that requires correction is the Faraday rotation induced by the ionospheric electrons, as it rotates the electric field, thereby modifying the Stokes vector components. The Faraday rotation angle $\omega$ (in degrees) can be approximated by

$$
\omega \approx K_{\mathrm{f}} \times \mathrm{B}(400) \times \cos \left(\Theta_{\mathrm{B}}\right) \times \sec (\theta) \times \mathrm{TEC}
$$

where $\mathrm{B}(400)$ is the geomagnetic field at an altitude of $400 \mathrm{~km}$ (in teslas), $K_{\mathrm{f}} \approx 6950^{\circ} \mathrm{T}^{-1} \mathrm{~m}^{2}, \Theta_{\mathrm{B}}$ is the angle between the

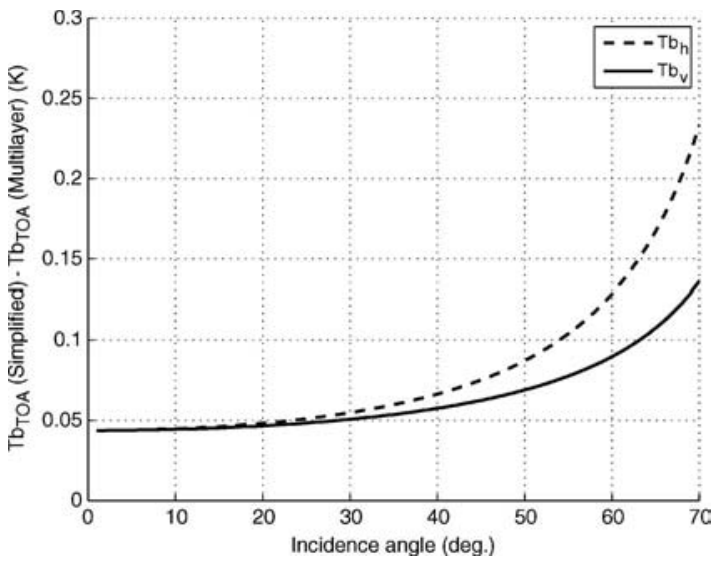

Fig. 3. Difference between $\mathrm{Tb}_{\mathrm{TOA}}$ simulated using both a simplified and a multilayer atmospheric model. We use a standard atmosphere profile (surface conditions: $P_{0}=1013 \mathrm{hPa}$ and $T_{0}=15{ }^{\circ} \mathrm{C}$ ) and a flat sea model (SSS $=$ $35 \mathrm{psu}$ and $\mathrm{SST}=15^{\circ} \mathrm{C}$ ).

direction of propagation and the Earth magnetic field, $\theta$ is the angle between nadir and the line of sight to the surface (viewing angle), and TEC is the vertical total electron content below the spacecraft, in TEC units $\left(1 \mathrm{TECu}=10^{16}\right.$ electrons $\left.\cdot \mathrm{m}^{-2}\right)$ [57], [58].

Le Vine and Abraham [58] have shown that, at 6 A.M., the error on $\mathrm{Tb}$ due to Faraday rotation can reach $1.5 \mathrm{~K}$, depending on the incidence angle. Neglecting the horizontal variations of the ionosphere at SMOS snapshot scale (about $1200 \times$ $1200 \mathrm{~km}$ ) leads to additional errors on $\mathrm{Tb}$ ranging from 0 to $0.6 \mathrm{~K}$. Longitudinal TEC variations are relatively small compared with latitudinal variations. Mean latitudinal Tb errors (averaged along all longitudes) range from 0 to $0.25 \mathrm{~K}$. The greatest error values are obtained at the geomagnetic equator and for high incidence angles [59].

Correcting for the Faraday rotation would require the TEC to be known with an accuracy of $0.5 \mathrm{TECu}$ to obtain an error on the SSS of $0.1 \mathrm{psu}$, but external TEC measurements fail to meet this requirement [18]. Yueh [57] has proposed a method to estimate the Faraday rotation angle from the third Stokes parameter, obtaining a residual error on $T_{\mathrm{h}}$ of less than $0.2 \mathrm{~K}$ for $\omega \leq 10^{\circ}$. Two options are considered in the L2SPP in order to minimize Faraday rotation effect on the SSS retrieval. The first option involves the use of the pseudofirst Stokes parameter defined in Section II-A to retrieve the SSS since it is almost insensitive to TEC. The second option involves the retrieval of the TEC from the SMOS multiangular measurements as part of the salinity retrieval procedure, as proposed in [18].

\section{E. Geometrical Projection From Earth to Antenna Reference Frame}

The iterative process to retrieve salinity from the SMOS measurements requires comparison of the measured and modeled Tbs, and this comparison is performed in the antenna polarization basis. Prior to this comparison, the forward model is used to compute the $\mathrm{Tb}$ associated with all physical processes, including rough surface emission, atmospheric self-emission, scattered galactic noise, and atmospheric attenuation of the upwelling brightness. At this point, the only omitted physical 
process affecting the $\mathrm{Tb}$ incident at the antenna is the Faraday rotation, and the result of this computation is the modeled Stokes vector at the top of the atmosphere in the surface polarization basis and with no consideration of the Faraday rotation.

The next step is to transport this Stokes vector to the SMOS antenna polarization basis, considering both the polarization basis rotation (which is merely a function of the viewing geometry) and the rotation of the electric field in the plane that is normal to the line of sight owing to the ionospheric Faraday rotation. After this step, a direct comparison of the modeled Stokes vector with the measured Stokes vector is possible. With the viewing geometry defined in [18], the transformation of the Stokes vector from the surface to the antenna polarization basis, with the Faraday rotation included, is given by (1). The rotation angle is the sum of the Faraday rotation angle and the additional counterclockwise rotation of the electricfield components associated with the clockwise rotation of the $(\mathrm{H}, \mathrm{V})$ polarization basis vectors (looking toward the antenna from the surface target).

\section{F. Iterative Scheme}

1) Method: A description of the retrieval method can be found in [60]. A maximum-likelihood Bayesian approach is used, taking advantage of the a priori information available about physical parameters. With this formalism, errors on $\mathrm{Tb}$ and on retrieved physical parameters are assumed to be Gaussian. In the antenna reference frame, the $\mathrm{Tb}$ modeled using the forward models described in the previous paragraphs $A^{\text {mod }}$ is fitted to a set of Tbs $A^{\text {meas }}$ reconstructed at different incidence angles by minimizing the cost function

$$
\chi^{2}=\sum_{n=1}^{N} \frac{\left[A_{n}^{\text {meas }}-A_{n}^{\text {mod }}\left(\theta_{n}, P_{i} \ldots\right)\right]^{2}}{\sigma_{A_{n}}^{2}}+\sum_{i=1}^{M} \frac{\left[P_{i}-P_{i 0}\right]^{2}}{\sigma_{P_{i 0}}^{2}} .
$$

Here, $N$ is the number of measurements available for retrieval at different incidence angles in $X$ and $Y$ polarizations. $N$ ranges from about 240 measurements at the center of the swath to about 20 at $600 \mathrm{~km}$ from the subsatellite track. $A_{n}^{\text {meas }}$ is simulated at incidence angles $\theta_{n}$ using one of the three forward models, with $\sigma_{A_{n}}^{2}=\sigma_{A \_ \text {meas } \_n}^{2}+\sigma_{A \_ \text {model } \_n}^{2}$, where $\sigma_{A \_ \text {meas } \_n}$ is the instrument noise simulated by the L1C prototype, and $\sigma_{A \_ \text {model } \_} n$ is an estimate of the model error. Both are given in the antenna reference frame (for the detailed expression of the model error in the antenna reference frame, see Appendix B). Typically, $\sigma_{A_{-} \text {meas_n }}$ ranges from 1.4 to $3.4 \mathrm{~K}$ (Fig. 4). In a first approach, we take the model error $\sigma_{A \_ \text {model_n} n}$ to be constant and equal to $0.5 \mathrm{~K}$. The physical parameters of the forward model $P_{i}$ consist of all of the parameters that may influence the modeled Tb, including SSS, SST, TEC, WS, and direction (or, alternatively, wind components), and possibly other roughness descriptors, depending on the roughness model used. $M$ is the number of parameters, and $P_{i 0}$ is the a priori estimate of the $P_{i}$ with a priori variance $\sigma_{P_{i 0}}^{2} . P_{i 0}$ values are specified a priori, whereas $P_{i}$ values are adjusted during the retrieval. A maximum of seven physical parameters can be retrieved with the current (a) On a subsatellite track

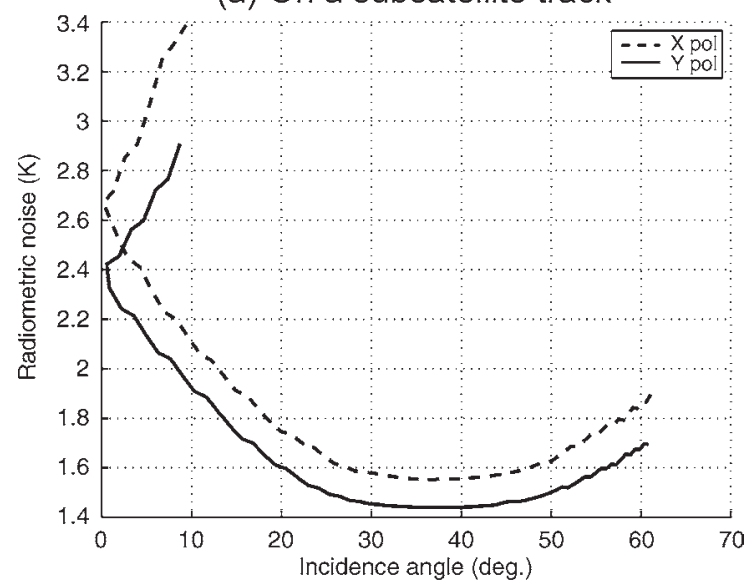

(b) At $540 \mathrm{~km}$ from the subsatellite track

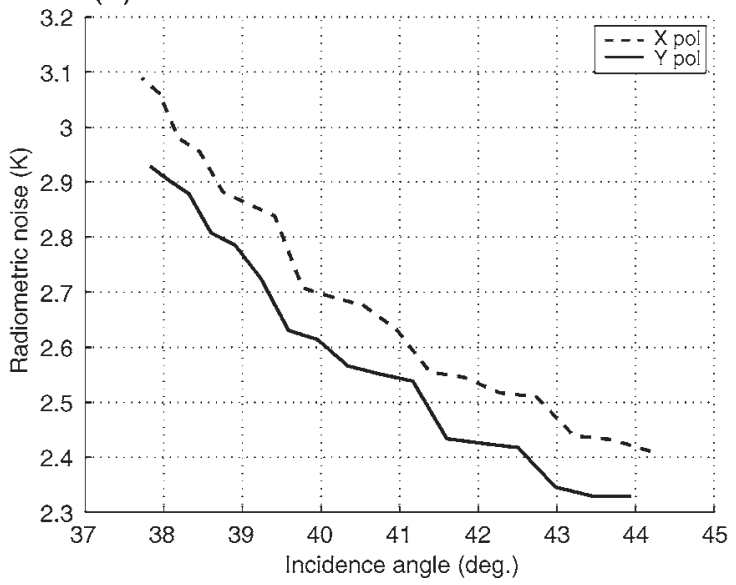

Fig. 4. Radiometric noise simulated with the L1C prototype (a) at the center and (b) at the edge of the FOV.

configuration. A general least square iterative algorithm [61] is used to retrieve the $P_{i}$ values that minimize the cost function (15), and this algorithm provides estimates of the theoretical variances $\sigma_{P_{i}}^{2}$ of the retrieved parameters. The theoretical error $\sigma_{P_{i}}$ on the geophysical parameter $P_{i}$ is computed by the Levenberg and Marquardt algorithm as follows:

$$
\left[\begin{array}{c}
\sigma_{P 1} \\
\cdots \\
\sigma_{P M}
\end{array}\right]=\sqrt{\operatorname{diag}\left(M^{-1}\right)}
$$

$M$ is pseudo-Hessian, with

$$
M=F^{\mathrm{T}} C_{0}^{-1} F
$$

where $C_{0}$ is the a posteriori covariance matrix (see Appendix B)

$$
\operatorname{diag}\left(C_{0}\right)=\left[\begin{array}{c}
\sigma_{A 1}^{2} \\
\cdots \\
\sigma_{A N}^{2} \\
\sigma_{P 10}^{2} \\
\cdots \\
\sigma_{P M 0}^{2}
\end{array}\right]
$$


$F$ is Jacobian

$F=\left(\frac{\partial A_{n}^{\bmod }}{\partial P_{i}}\right), \quad n=1, \ldots, N$, and $i=1, \ldots, M$

and the superscript ${ }^{\mathrm{T}}$ is the transpose operator.

2) Data: For the operational processor, all the auxiliary data required to specify prior parameters $P_{i 0}$ (SST, wind descriptors, atmospheric parameters, etc.) are obtained from the ECMWF. Auxiliary data are preprocessed to generate physical parameters required by the algorithm and to interpolate these physical parameters onto the fixed Earth grid on which the retrievals are performed. The L1C product includes one TEC value per snapshot, which is produced by the International Global Navigation Satellite System Service (IGS) [62]. In case the IGS data are not available, the L1C processor uses the TEC produced by the International Reference Ionosphere (IRI2001) model [63] instead. For each grid point, there are as many TEC values as $\mathrm{Tb}$ values; thus, we use the median TEC as prior value when the TEC is retrieved. The uncertainties $\sigma_{P_{i 0}}$ associated with the geophysical parameters are set to appropriate constant values. The one exception is the SSS, which is unconstrained during the retrieval procedure.

With the L2SPP, we retain the possibility of using alternative sources of auxiliary data. The computation of the uncertainties and the possibility of regional biases in the auxiliary data require further study, as both have an impact on the SSS retrieval quality.

\section{G. Output Product}

The L2SPP output product includes, for each grid point, the three salinities retrieved with the three forward models, their associated theoretical uncertainty, and the SST and WS prior values. The "confidence flags" and descriptors generated by the L2SPP [10] provide an indication of the quality of the retrieval (i.e., poor fit quality, no convergence, estimate of the total uncertainty on the retrieved SSS, etc.) and indicate the presence of measured $\mathrm{Tb}$ outliers, potential sun-glint contamination, sky radiation contamination, etc. The processor also produces "science flags," which are raised whenever the geophysical conditions, such as the presence of ice, heavy rain, or the proximity of land, might impact the quality of the retrieval.

The Level 2 Processor does not perform any spatial or temporal averaging of the retrieved parameters; potential reduction in random or systematic (e.g., bias) errors in the retrieved parameters by temporal or spatial averaging or by the introduction of additional auxiliary parameters is left to further processing at the so-called "Level 3" stage.

\section{IDEALIZED RETRIEVALS}

\section{A. Method}

A set of idealized tests has been performed in order to verify that the prototype performs as expected. For this purpose, we perform retrievals over about 7300 grid points of the $15-\mathrm{km}$ ISEA grid. For models 1 and 3, retrievals are performed on WS (on $u^{*}$ for model 2, Table III). Errors are assumed to be
TABLE III

SETS OF PARAMETERs RETRIEVED FOR THE Two RETRIEVAL MODES

(DP AND ST1) AND THE THREE FORWARD MODELS DURING THE IDEALIZED TESTS DESCRIBED IN SECTION III. WS IS THE 10-m NEUTRAL EQUIVALENT WS. $u$ AND $\nu$ ARE THE Wind COMPONENTS. $\Omega$ IS THE INVERSE WAVE AGE, AND $\Phi$ IS THE WIND DIRECTION

\begin{tabular}{|c|c|c|}
\hline Forward model & Dual polarization (DP) & Stokes 1 (ST1) \\
\hline \multirow[t]{4}{*}{ Model 1} & SSS & SSS \\
\hline & SST & SST \\
\hline & TEC & WS or $(u, v)$ \\
\hline & WS or $(u, v)$ & \\
\hline \multirow[t]{6}{*}{ Model 2} & SSS & SSS \\
\hline & SST & SST \\
\hline & TEC & $\mathrm{u}^{*}$ \\
\hline & $\mathrm{u}^{*}$ & $\Omega$ \\
\hline & $\Omega$ & $\Phi$ \\
\hline & $\Phi$ & \\
\hline \multirow[t]{4}{*}{ Model 3} & SSS & SSS \\
\hline & TEC & WS \\
\hline & WS & Hs \\
\hline & Hs & \\
\hline
\end{tabular}

Gaussian, which can lead to unphysical negative WS ${ }^{\text {prior }}$ values at low WS. To avoid this, retrievals have also been performed with model 1 on wind components $u$ and $\nu$ with Gaussian noise added to $u$ and $\nu$, naturally inducing a WS error with a Rayleigh distribution (see Appendix A). This issue is discussed in Section III-B2e. Retrievals are performed for the three models over five homogeneous scenes (Table IV). Simulations have also been performed at $25^{\circ} \mathrm{C}$ and $5{ }^{\circ} \mathrm{C}$ for SSS $=35 \mathrm{psu}$. With respect to the results obtained at $25^{\circ} \mathrm{C}$ and $38 \mathrm{psu}$, and at $5{ }^{\circ} \mathrm{C}$ and $33 \mathrm{psu}$, the errors on SSS show similar trends and vary by less than $6 \%$ at the center of the swath and by less than $3 \%$ at the edge for model 1 in the nominal retrieval configuration. Different retrieval conditions have also been tested (Table V).

The resulting biases and errors on the retrieved SSS are averaged within eight $150-\mathrm{km}$-wide swath zones, containing about 1000 grid points each, to reduce noise and improve the reliability of error statistics. We compute the bias $b$

$$
b=\operatorname{median}\left(P_{i}\right)_{\mathrm{Ng}}-P_{i}^{\text {true }} .
$$

The median of the retrieved geophysical parameter $P_{i}$ is computed over the $\mathrm{Ng}$ grid points of the zone. $P_{i}^{\text {true }}$ is the true value of $P_{i}$. We compute the mean theoretical error $\sigma$

$$
\sigma=\sqrt{\frac{\sum_{k=1}^{\mathrm{Ng}} \sigma_{P_{i}, k}^{2}}{\mathrm{Ng}}}
$$

and the root-mean-square (rms) error

$$
\text { rmse }=\sqrt{\frac{1}{\mathrm{Ng}} \sum_{k=1}^{\mathrm{Ng}}\left(P_{i, k}-P_{i}^{\text {true }}\right)^{2}-\bar{B}_{P_{i}}^{2}}
$$

with

$$
\bar{B}_{P_{i}}=\frac{1}{\mathrm{Ng}} \sum_{k=1}^{\mathrm{Ng}}\left(P_{i, k}-P_{i}^{\text {true }}\right) .
$$


TABLE IV

Geophysical Parameter Values for the Five Homogeneous Scenes Used in the Retrievals

\begin{tabular}{ccccc}
\hline Scene & SSS (psu) & SST $\left({ }^{\circ} \mathbf{C}\right)$ & WS $\left(\mathbf{m s}^{-1}\right)$ & TEC (TECu) \\
\hline Reference & 35 & 15 & 7 & 10 \\
\hline High SSS \& SST & 38 & 25 & 7 & 10 \\
\hline Low SSS \& SST & 33 & 5 & 7 & 10 \\
\hline High WS & 35 & 15 & 15 & 10 \\
\hline Low WS & 35 & 15 & 3 & 10 \\
\hline
\end{tabular}

TABLE V

Retrieval Conditions Tested With Model 1

\begin{tabular}{llll}
\hline $\begin{array}{l}\text { Retrieval } \\
\text { conditions }\end{array}$ & Prior values $\mathrm{P}_{\mathrm{i}}$ & Uncertainties $\sigma_{\mathrm{Pi}}$ & Biases \\
\hline Nominal & $\begin{array}{l}\text { PSSS }=35 \text { psu. } \\
\text { All other priors set to a } \\
\text { random value around the } \\
\text { true value. }\end{array}$ & $\begin{array}{l}\sigma_{\mathrm{SSS}}=100 \mathrm{psu} \\
\sigma_{\mathrm{SST}}=1{ }^{\circ} \mathrm{C} \\
\sigma_{\mathrm{WS}}=1.5 \mathrm{~ms}^{-1} \\
\sigma_{\mathrm{TEC}}=5 \mathrm{TECu}\end{array}$ & None \\
\hline $\begin{array}{l}\text { SST perfectly } / \\
\text { poorly known }\end{array}$ & Nominal & $\begin{array}{l}\sigma_{\mathrm{SST}}=0^{\circ} \mathrm{C} / 2^{\circ} \mathrm{C} \\
\text { All other } \sigma: \text { nominal }\end{array}$ & None \\
\hline $\begin{array}{l}\text { WS perfectly / } \\
\text { poorly known }\end{array}$ & Nominal & $\begin{array}{l}\sigma_{\mathrm{WS}}=0 \mathrm{~ms}^{-1} / 3 \mathrm{~ms}^{-1} \\
\text { All other } \sigma: \text { nominal }\end{array}$ & None \\
\hline Biases on SST & Nominal & Nominal & $\begin{array}{l}\mathrm{B}_{\mathrm{SST}}=-0.5^{\circ} \mathrm{C} / \\
-1^{\circ} \mathrm{C} /-2^{\circ} \mathrm{C}\end{array}$ \\
\hline Biases on WS & Nominal & Nominal & $\begin{array}{l}\mathrm{B}_{\mathrm{WS}}=-1 \mathrm{~ms} \mathrm{~ms}^{-1} / \\
-2 \mathrm{~ms}\end{array}$ \\
\hline Biases on TEC & Nominal & Nominal & $\begin{array}{l}\mathrm{B}_{\mathrm{TEC}}=-5 \mathrm{TECu} / \\
-10 \mathrm{TECu}\end{array}$ \\
\hline
\end{tabular}

\section{B. Results}

1) SSS Retrieved in Nominal Conditions (Three Models): First, we examine the statistical behavior of the retrievals. Fig. 5(a) shows the normalized SSS error (i.e., the ratio of the difference between the retrieved and true SSS and the theoretical error) for the three models, and Fig. 5(b) shows the theoretical and rms errors for retrievals performed for the reference scene in nominal retrieval conditions. The three normalized SSS errors follow a distribution close to Gaussian, showing that the linear model approximation does not generate major artifacts. The theoretical and rms errors are very similar, showing that the retrieval behaves well statistically. In the rest of this paper, only theoretical errors are shown, as we have found them to be representative of the rms errors. Errors increase at the edge of the swath due to greater radiometric noise and to decreasing number of available measurements (Fig. 5(b), see also Fig. 4). Differences obtained with the three models reflect different sensitivities of $\mathrm{Tb}$ to roughness parameters and our present knowledge of L-band emissivity modeling. The error is globally smaller for model $2(0.5-1.5 \mathrm{psu})$ than for model 1 (0.6-1.6 psu) and model 3 (0.5-1.7 psu).

Fig. 6 shows the influence of the prior WS, i.e., WS ${ }^{\text {prior }}$, on the retrieved SSS for the three models. A high (low) value of $\mathrm{WS}^{\text {prior }}$ results in a high (low) $\mathrm{Tb}^{\text {mod }}$ that is not entirely corrected during the iterative process, and consequently, the SSS is overestimated (underestimated). Regardless of the roughness emissivity model used, the scatter of the points is larger at the edge of the swath than at the center, with the lowest scatter observed for model 2. Model 3 shows the largest scatter at the edge of the swath, and model 1 shows the largest scatter at the center of the swath, as already observed for the theoretical uncertainties [Fig. 5(b)].

In the rest of this section, we show the results obtained with model 1 to illustrate the general behavior of the retrieval.
Models 2 and 3 have also been tested, and the results follow the same trends as those of model 1.

2) SSS Retrieved With Model 1:

a) Nominal conditions: Table VI gives the error and the bias for the retrieved SSS, SST, WS, and TEC for the five homogeneous scenes specified in Table IV, under nominal retrieval conditions (Table V). The greatest error (1.22 psu at the center of the swath and 2.44 psu at the edge) on SSS is obtained at $5{ }^{\circ} \mathrm{C}$, due to the low sensitivity of Tb to SSS at low SST. In all configurations, the error on the retrieved SST remains equal to the error on the prior $\operatorname{SST}\left(1^{\circ} \mathrm{C}\right)$, showing no improvement of SST during the retrieval. On the other hand, WS is improved during the retrieval, with errors smaller than $1.5 \mathrm{~m} \cdot \mathrm{s}^{-1}$ at the center of the swath $\left(1.12-1.39 \mathrm{~m} \cdot \mathrm{s}^{-1}\right)$. The smallest error on WS is obtained at $3 \mathrm{~m} \cdot \mathrm{s}^{-1}$, where the sensitivity of $\mathrm{Tb}$ to $\mathrm{WS}$ is the greatest. However, the greatest bias on the retrieved SSS ( $-0.11 \mathrm{psu}$ at the edge of the swath) is also obtained in this configuration. This is discussed in Section III-B2e. In all configurations but one (high WS), the error on the retrieved TEC is higher at the center of the swath (2.73-2.96 TECu) than at the edge $(2.56-2.59 \mathrm{TECu})$ because the TEC is more sensitive to the radiometric noise at the center of the swath.

b) Noise study at $15{ }^{\circ} \mathrm{C}$ : Fig. 7 shows the SSS error obtained with model 1 in DP and first Stokes (ST1) modes for various levels of noise on SST and WS. In ST1 mode, the curves are symmetrical about the subsatellite track; the asymmetry observed in DP mode is associated with the Faraday rotation. In both cases, the smallest SSS errors ( 0.4 at the center of the swath to $1.4 \mathrm{psu}$ at the edge in DP mode) and the greatest SSS errors (0.7-2.1 psu in DP mode) are observed for perfectly known and poorly known WS, respectively, and this result emphasizes the large dependence of the SSS error to the errors on roughness parameters. By contrast, the SSS error is only weakly sensitive to the SST error due to the low sensitivity of 
(a)

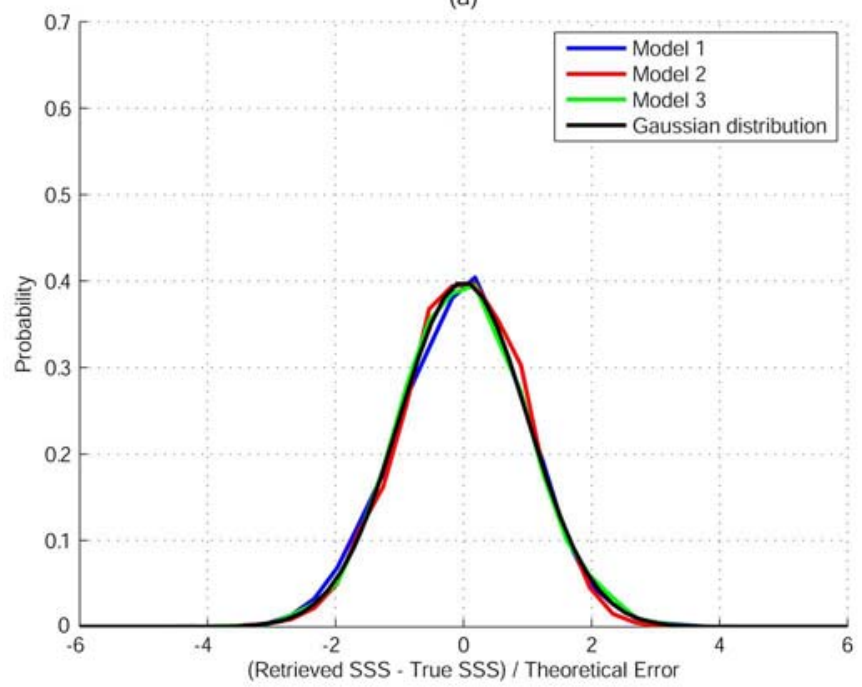

(b)

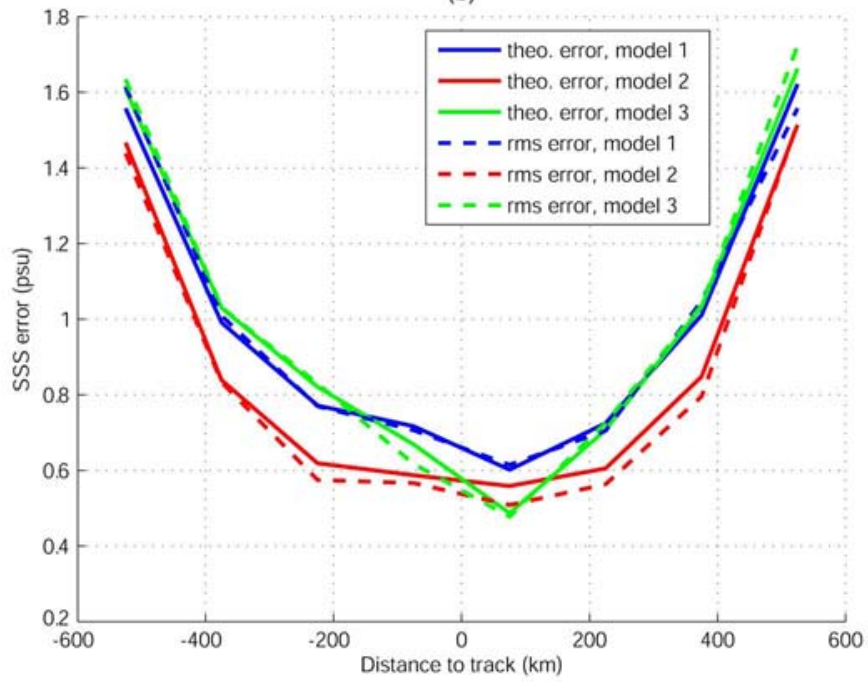

Fig. 5. (a) Normalized retrieved SSS error for the three models (model 1 in blue, 2 in red, 3 in green, homogeneous scene, nominal conditions) and (black) Gaussian distribution. (b) Theoretical error (solid lines) and rms error (dashed lines) on the retrieved SSS as a function of distance to track for the three models. DP mode, reference scene (SSS $=35 \mathrm{psu}, \mathrm{SST}=15{ }^{\circ} \mathrm{C}$, and $\left.\mathrm{WS}=7 \mathrm{~m} \cdot \mathrm{s}^{-1}\right)$.

$\mathrm{Tb}$ to SST at $15^{\circ} \mathrm{C}$. In the nominal retrieval conditions, the SSS error is greater in ST1 mode than in DP mode, by $30 \%$ at the center of the swath and by less than $1 \%$ at the edge. The ST1 mode is also more sensitive to the increasing errors on WS, showing a better ability of the DP mode to correct for large WS errors.

Table VII shows that the error on the retrieved SST remains equal to the error on the prior SST, confirming that the SST is not improved by the retrieval. At the center of the swath, the retrieved WS is significantly improved in the case of poorly known prior WS. The error on the retrieved WS is about $1 \mathrm{~m} \cdot \mathrm{s}^{-1}$ lower than the a priori error. However, the error on the retrieved SSS is greater in this case (1.02 psu at the center of the swath and 2.04 psu at the edge), as well as the error on the retrieved TEC (3.15 TECu at the center of the swath). (a) Model 1

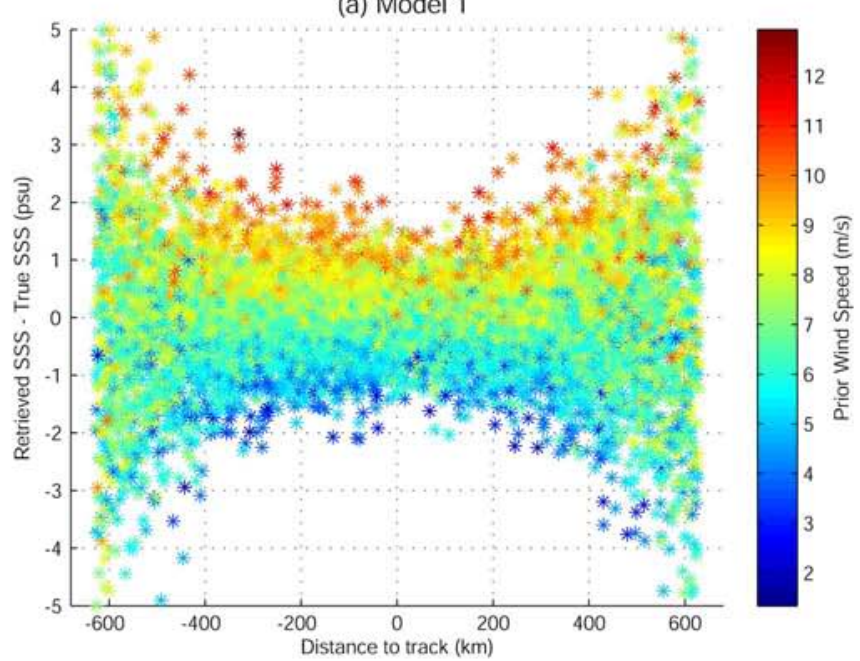

(b) Model 2

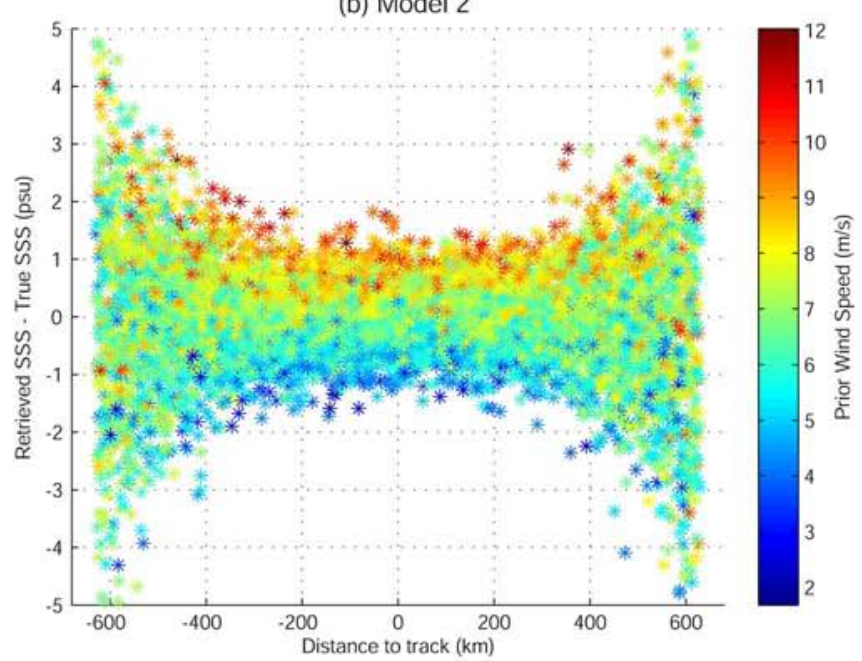

(c) Model 3

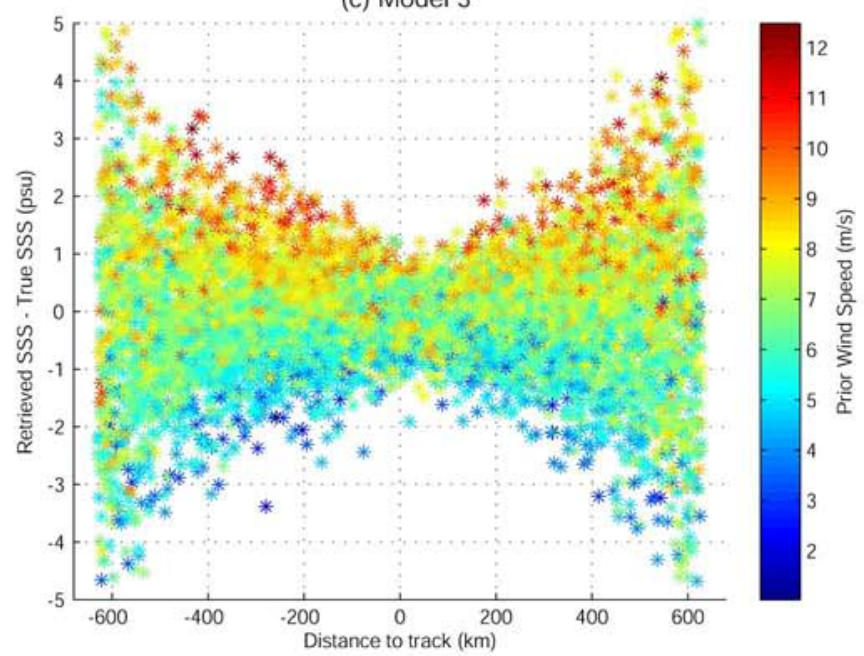

Fig. 6. SSS difference (retrieved minus "true" SSS) as a function of distance to track for various WS ${ }^{\text {prior }}$ 's for (a) model 1, (b) model 2, and (c) model 3. DP mode, reference scene $\left(\mathrm{SSS}=35 \mathrm{psu}, \mathrm{SST}=15^{\circ} \mathrm{C}\right.$, and $\left.\mathrm{WS}=7 \mathrm{~m} \cdot \mathrm{s}^{-1}\right)$.

c) Noise study at $25^{\circ} \mathrm{C}$ and $5{ }^{\circ} \mathrm{C}$ : Fig. 8(a) and (b) shows the SSS error obtained in DP mode for high and low SSS and SST scenes. The SSS error is greater at $5{ }^{\circ} \mathrm{C}$ than at $15{ }^{\circ} \mathrm{C}$ 
TABLE VI

Geophysical Parameters Retrieved With Model 1 Over the Five Homogeneous Scenes (DP Mode, Nominal Retrieval Conditions). at the Center of the Swath (Distance to the Subsatellite Track Smaller Than $300 \mathrm{~km}$ ) and at the Edge of the Swath (Distance Greater Than $300 \mathrm{~km})$, We Compute $\sigma=\sqrt{\left(\sum_{k=1}^{N g} \sigma_{P i, k}^{2} /(\mathrm{Ng})\right)}$ and $b=\operatorname{median}\left(P_{i}\right)_{\mathrm{Ng}}-P_{i}^{\text {true }} \cdot \sigma_{P_{i}, k}$ Is the Theoretical ERror of the

Geophysical Parameter $P_{i}$ Retrieved at Grid Point $k$, And Ng Is the Number of Grid Points. The Median of $P_{i}$ Is Computed Over the Ng Grid Points of the Zone (Center or Edge of Swath), and $P_{i}^{\text {true }}$ Is the True Geophysical Parameter Value

\begin{tabular}{|c|c|c|c|c|c|c|c|c|c|}
\hline \multirow{2}{*}{ Scene } & \multirow{2}{*}{$\begin{array}{l}\text { Location } \\
\text { in swath }\end{array}$} & \multicolumn{2}{|c|}{ SSS (psu) } & \multicolumn{2}{|c|}{$\operatorname{SST}\left({ }^{\circ} \mathrm{C}\right)$} & \multicolumn{2}{|c|}{$\mathrm{WS}\left(\mathrm{ms}^{-1}\right)$} & \multicolumn{2}{|c|}{ TEC (TECu) } \\
\hline & & $\sigma$ & $\mathrm{b}$ & $\sigma$ & $\mathrm{b}$ & $\sigma$ & $b$ & $\sigma$ & $\mathrm{b}$ \\
\hline \multirow{2}{*}{ Reference } & Center & 0.71 & -0.02 & 1.00 & 0.03 & 1.28 & -0.02 & 2.73 & -0.03 \\
\hline & Edge & 1.50 & & 00 & 0 & 1.49 & 0.00 & 2.57 & 0.02 \\
\hline \multirow{2}{*}{ High SST } & Center & 0.57 & -0.0 & 1.00 & 0.06 & 1.28 & -0.01 & 2.74 & -0.06 \\
\hline & Edge & 1.14 & 0.01 & 1.00 & 0.01 & 1.49 & -0.01 & 2.59 & 0.03 \\
\hline \multirow{2}{*}{ Low SST } & Center & 1.22 & -0.01 & 1.00 & 0.01 & 1.29 & -0.02 & 2.74 & 0.03 \\
\hline & Edge & 2.44 & 0.00 & 1.00 & 0.01 & 1.49 & 0.00 & 2.59 & -0.06 \\
\hline \multirow{2}{*}{ High WS } & Center & 0.80 & -0.06 & 1.00 & 0.02 & 1.39 & -0.02 & 2.51 & 0.02 \\
\hline & Edge & 1.52 & 0.00 & 1.00 & 0.00 & 1.49 & 0.00 & 2.59 & 0.05 \\
\hline \multirow{2}{*}{ Low WS } & Center & 0.71 & -0.05 & 1.00 & 0.03 & 1.12 & -0.07 & 2.96 & 0.01 \\
\hline & Edge & 1.68 & -0.11 & 1.00 & 0.01 & 1.46 & -0.01 & 2.56 & 0.00 \\
\hline
\end{tabular}

(a) Dual pol

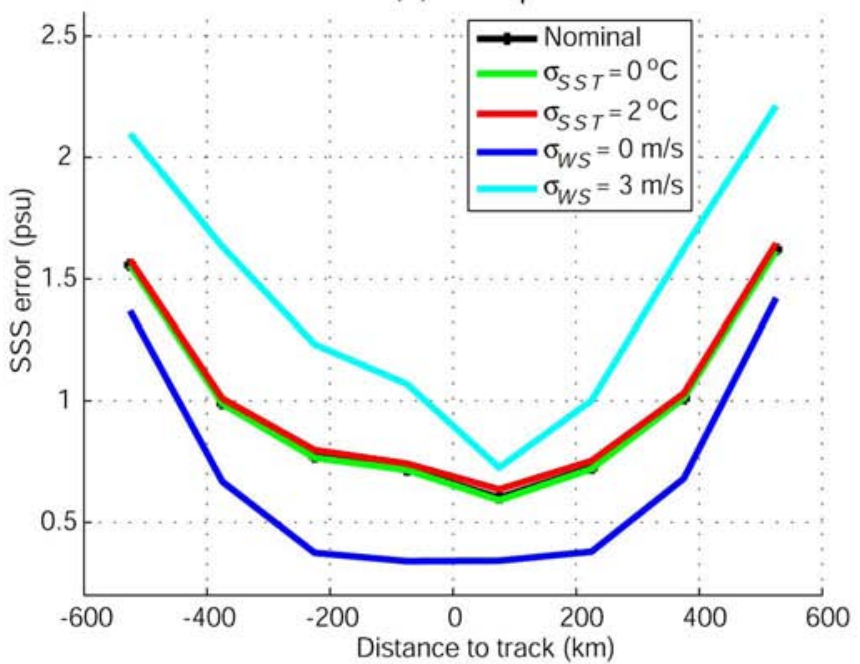

(b) Stokes 1

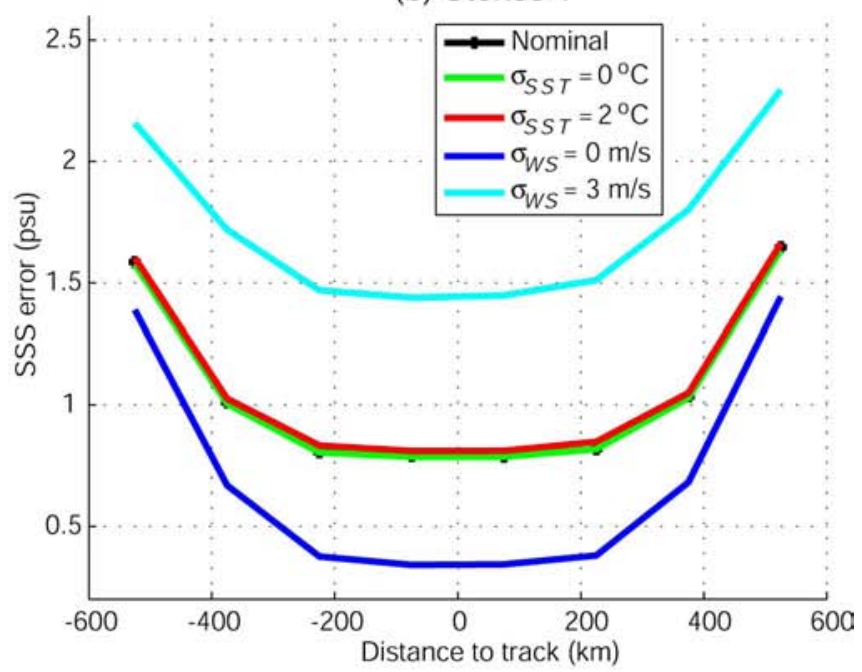

Fig. 7. SSS error as a function of distance to track for model 1 and different levels of uncertainty on SST and WS (a) in DP mode and (b) in ST1 mode. $\mathrm{SSS}=35 \mathrm{psu}, \mathrm{SST}=15^{\circ} \mathrm{C}$, and $\mathrm{WS}=7 \mathrm{~m} \cdot \mathrm{s}^{-1}$.

(in nominal conditions: $1.1 \mathrm{psu}$ at the center of the swath to $2.5 \mathrm{psu}$ at the edge and 0.6-1.6 psu, respectively; see also Fig. 7). Conversely, the SSS error is slightly smaller at $25{ }^{\circ} \mathrm{C}$, with $0.5 \mathrm{psu}$ at the center and $1.2 \mathrm{psu}$ at the edge of the swath. This reflects the lower Tb sensitivity to SSS at lower SST. In all cases, the SSS errors vary by less than 0.2 psu when the SST errors vary by less than $1{ }^{\circ} \mathrm{C}$.

d) Noise study at 15 and $3 \mathrm{~m} \cdot \mathrm{s}^{-1}$ : Fig. 8(c) and (d) shows the SSS errors in DP mode obtained in high and low WS conditions. The SSS errors at $3 \mathrm{~m} \cdot \mathrm{s}^{-1}$ are slightly smaller than those obtained at $7 \mathrm{~m} \cdot \mathrm{s}^{-1}(0.5$ and $0.6 \mathrm{psu}$ at the center of the swath in nominal conditions, respectively; see also Fig. 7). The SSS errors are slightly greater at $15 \mathrm{~m} \cdot \mathrm{s}^{-1}$, with $0.7 \mathrm{psu}$ at the center of the swath. At the center of the swath, the error on WS is reduced more at $3 \mathrm{~m} \cdot \mathrm{s}^{-1}$ than at $15 \mathrm{~m} \cdot \mathrm{s}^{-1}$ because of the greater sensitivity of Tb to WS at low WS.

e) Bias related to WS error modeling: In the case of no bias in auxiliary parameters and $\mathrm{Tb}$, the retrieved SSS is almost free of bias. The retrieval method used in the L2SPP implicitly assumes that the distribution of the WS error is Gaussian. Under this assumption and at low WS, WS ${ }^{\text {prior }}$ can become negative, which is unphysical. Avoidance of this problem is the motivation to use wind components rather than WS in the retrieval with model 1. Freilich [64] and Stoffelen [65] have shown that due to the positive definite nature of WS, it is unrealistic to assume a Gaussian noise on WS. They show that it is more reasonable to assume isotropic random errors on wind components either measured in situ or deduced from meteorological models. However, at low WS, random noise on wind components leads to bias on WS. At present, this flaw is not corrected in the prototype. Fig. 9 shows that, at the center of the swath, the bias on the retrieved WS ranges from $0.6 \mathrm{~m} \cdot \mathrm{s}^{-1}$ at low WS to $0 \mathrm{~m} \cdot \mathrm{s}^{-1}$ at high WS. This is consistent with theory (see Appendix A). The theoretical WS biases due to the use of wind components in the retrieval are $0.4 \mathrm{~m} \cdot \mathrm{s}^{-1}$ at $3 \mathrm{~m} \cdot \mathrm{s}^{-1}, 0.17 \mathrm{~m} \cdot \mathrm{s}^{-1}$ at $7 \mathrm{~m} \cdot \mathrm{s}^{-1}$, and $0.1 \mathrm{~m} \cdot \mathrm{s}^{-1}$ at $15 \mathrm{~m} \cdot \mathrm{s}^{-1}$, which are equivalent to SSS biases of $0.16,0.07$, and 0.04 psu, respectively. Fig. 10 shows that the SSS bias 
TABLE VII

Geophysical Parameters Retrieved With Model 1 for Different Retrieval Conditions (DP Mode, Reference Scene). At the Center of the Swath (Distance to the Subsatellite Track Smaller Than $300 \mathrm{~km}$ ) and at the Edge of the Swath (Distance Greater Than $300 \mathrm{~km})$, We Compute $\sigma=\sqrt{\left(\sum_{k=1}^{\mathrm{Ng}} \sigma_{P_{i}, k}^{2} /(\mathrm{Ng})\right)}$ AND $b=\operatorname{median}\left(P_{i}\right)_{\mathrm{Ng}}-P_{i}^{\text {true }} \cdot \sigma_{P_{i}, k}$ Is the THEORETICAL ERRor OF THE Geophysical Parameter $P_{i}$ Retrieved at Grid Point $k$, and Ng Is the Number of Grid Points. The Median of $P_{i}$ Is Computed Over the Ng Grid Points of the Zone (Center or Edge of Swath), and $P_{i}^{\text {true }}$ Is the True Geophysical Value

\begin{tabular}{|c|c|c|c|c|c|c|c|c|c|}
\hline \multirow{2}{*}{$\begin{array}{c}\text { Retrieval } \\
\text { conditions }\end{array}$} & \multirow{2}{*}{$\begin{array}{l}\text { Location } \\
\text { in swath }\end{array}$} & \multicolumn{2}{|c|}{ SSS (psu) } & \multicolumn{2}{|c|}{ SST $\left({ }^{\circ} \mathrm{C}\right)$} & \multicolumn{2}{|c|}{ WS $\left(\mathrm{ms}^{-1}\right)$} & \multicolumn{2}{|c|}{$\overline{\mathrm{TEC}(\mathrm{TECu})}$} \\
\hline & & $\sigma$ & $\mathrm{b}$ & $\sigma$ & $\mathrm{b}$ & $\sigma$ & b & $\sigma$ & $\mathrm{b}$ \\
\hline \multirow{2}{*}{ Nominal } & Center & 0.71 & -0.02 & 1.00 & 0.03 & 1.28 & -0.02 & 2.73 & -0.03 \\
\hline & Edge & 1.50 & 0.04 & 1.00 & 0.00 & 1.49 & 0.00 & 2.57 & 0.02 \\
\hline \multirow[b]{2}{*}{$\sigma_{\mathrm{SST}}=0^{\circ} \mathrm{C}$} & Center & 0.70 & -0.02 & 0.00 & 0.00 & 1.28 & -0.06 & 2.73 & 0.05 \\
\hline & Edge & 1.49 & 0.04 & 0.00 & 0.00 & 1.49 & 0.00 & 2.57 & 0.02 \\
\hline \multirow{2}{*}{$\sigma_{\mathrm{SST}}=2^{\circ} \mathrm{C}$} & Center & 0.73 & -0.09 & 1.98 & -0.05 & 1.29 & -0.05 & 2.74 & -0.04 \\
\hline & Edge & 1.52 & -0.01 & 2.00 & -0.03 & 1.49 & -0.02 & 2.58 & 0.02 \\
\hline \multirow{2}{*}{$\sigma_{\mathrm{WS}}=0 \mathrm{~ms}^{-1}$} & Center & 0.36 & -0.03 & 1.00 & 0.02 & 0.00 & 0.00 & 2.32 & -0.06 \\
\hline & Edge & 1.29 & -0.01 & 1.00 & -0.02 & 0.00 & 0.00 & 2.56 & 0.04 \\
\hline \multirow{2}{*}{$\sigma_{\mathrm{WS}}=3 \mathrm{~ms}^{-1}$} & Center & 1.02 & -0.01 & 1.00 & 0.02 & 2.02 & -0.01 & 3.15 & -0.06 \\
\hline & Edge & 2.04 & -0.01 & 1.00 & -0.03 & 2.89 & -0.01 & 2.61 & -0.10 \\
\hline \multirow{2}{*}{$\mathrm{B}_{\mathrm{SST}}=-0.5^{\circ} \mathrm{C}$} & Center & 0.72 & -0.06 & 1.00 & -0.46 & 1.28 & -0.01 & 2.74 & -0.11 \\
\hline & Edge & 1.53 & 0.00 & 1.00 & -0.49 & 1.49 & 0.02 & 2.57 & 0.01 \\
\hline \multirow{2}{*}{$\mathrm{B}_{\mathrm{SST}}=-1{ }^{\circ} \mathrm{C}$} & Center & 0.73 & -0.13 & 1.00 & -1.01 & 1.28 & -0.12 & 2.74 & -0.09 \\
\hline & Edge & 1.56 & -0.05 & 1.00 & -1.00 & 1.48 & 0.02 & 2.57 & 0.02 \\
\hline \multirow{2}{*}{$B_{S S T}=-2{ }^{\circ} \mathrm{C}$} & Center & 0.77 & -0.21 & 1.00 & -2.00 & 1.28 & -0.08 & 2.74 & -0.18 \\
\hline & Edge & 1.62 & -0.16 & 1.00 & -1.96 & 1.48 & 0.00 & 2.58 & -0.03 \\
\hline \multirow{2}{*}{$\mathrm{B}_{\mathrm{WS}}=-1 \mathrm{~ms}^{-1}$} & Center & 0.68 & -0.35 & 1.00 & -0.01 & 1.28 & -0.75 & 2.69 & 0.21 \\
\hline & Edge & 1.48 & -0.41 & 1.00 & -0.01 & 1.48 & -0.90 & 2.56 & 0.03 \\
\hline \multirow{2}{*}{$B_{\mathrm{WS}}=-2 \mathrm{~ms}^{-1}$} & Center & 0.66 & -0.65 & 1.00 & -0.01 & 1.28 & -1.49 & 2.67 & 0.54 \\
\hline & Edge & 1.49 & -0.87 & 1.00 & 0.00 & 1.48 & -1.94 & 2.56 & -0.01 \\
\hline \multirow{2}{*}{$\mathrm{B}_{\mathrm{TEC}}=-5 \mathrm{TECu}$} & Center & 0.71 & -0.01 & 1.00 & 0.03 & 1.28 & 0.03 & 2.77 & -0.95 \\
\hline & Edge & 1.50 & 0.00 & 1.00 & -0.02 & 1.48 & 0.00 & 2.57 & -1.07 \\
\hline \multirow{2}{*}{$\mathrm{B}_{\mathrm{TEC}}=-10 \mathrm{TECu}$} & Center & 0.71 & 0.00 & 1.00 & 0.01 & 1.28 & 0.06 & 2.79 & -1.38 \\
\hline & Edge & 1.50 & 0.00 & 1.00 & 0.03 & 1.48 & -0.01 & 2.57 & -1.50 \\
\hline
\end{tabular}

when wind components or WS is retrieved differs the most at $3 \mathrm{~m} \cdot \mathrm{s}^{-1}$ (with a difference ranging from 0.08 to $0.3 \mathrm{psu}$ ) and the less at $15 \mathrm{~m} \cdot \mathrm{s}^{-1}$ (with a difference ranging from 0 to $0.05 \mathrm{psu}$ ).

f) Influence of biased auxiliary parameters: In DP mode, the strongest biases on SSS (more than 0.3 psu in absolute value) are observed for $B_{\mathrm{WS}}=-1$ and $-2 \mathrm{~m} \cdot \mathrm{s}^{-1}$ [Fig. 11(a)]. These values are comparable with those obtained in previous studies [6]. Moreover, both of these biases are smaller in absolute value at the center of the swath $(0.3$ and 0.5 psu, respectively) than at the edge ( 0.4 and 0.9 psu, respectively). On the other hand, the SSS biases obtained in ST1 mode for $B_{\mathrm{WS}}=-1$ and $-2 \mathrm{~m} \cdot \mathrm{s}^{-1}$ do not vary across track $[0.5$ and 0.9 psu, respectively, Fig. 11(b)]. This shows that the DP mode is better able to correct for the WS biases close to the center of the swath. The reason is that the Tb measured by SMOS at the center of the swath covers a large range of incidence angles (from $0^{\circ}$ to about $60^{\circ}$ ) relative to the $\mathrm{Tb}$ measured at the edge of the swath (from about $42^{\circ}$ to $48^{\circ}$ ). The sensitivity of the first Stokes parameter I to WS increases with WS but varies weakly with the incidence angle. At $7 \mathrm{~m} / \mathrm{s}$, it ranges from $0.5 \mathrm{~K} \cdot \mathrm{ms}^{-1}$ at $0^{\circ}$ to $0.55 \mathrm{~K} \cdot \mathrm{ms}^{-1}$ at $40^{\circ}$. By contrast, the sensitivity of the second Stokes parameter $\left(Q=T_{\mathrm{v}}-T_{\mathrm{h}}\right)$ to WS varies strongly with the incidence angle, particularly at low and moderate WSs. At $7 \mathrm{~m} \cdot \mathrm{s}^{-1}$, it ranges from $-0.3 \mathrm{~K} \cdot \mathrm{ms}^{-1}$ at $56^{\circ}$ to $0 \mathrm{~K} \cdot \mathrm{ms}^{-1}$ at $0^{\circ}$, and at $3 \mathrm{~m} \cdot \mathrm{s}^{-1}$, it ranges from $-0.6 \mathrm{~K} \cdot \mathrm{ms}^{-1}$ at $56^{\circ}$ to
$0 \mathrm{~K} \cdot \mathrm{ms}^{-1}$ at $0^{\circ}$. In DP mode and at the center of the swath, the bias correction on the retrieved WS is $0.25 \mathrm{~m} \cdot \mathrm{s}^{-1}$ when the bias on the prior is equal to $-1 \mathrm{~m} \cdot \mathrm{s}^{-1}$ and is $0.5 \mathrm{~m} \cdot \mathrm{s}^{-1}$ when it is equal to $-2 \mathrm{~m} \cdot \mathrm{s}^{-1}$ (Table VII). In the first case, there is a 0.21-TECu bias on the retrieved TEC, and in the second case, there is a 0.54-TECu bias, due to the fact that the second Stokes parameter is sensitive to both the WS and the TEC.

In DP mode, the SSS biases resulting from biases on TEC are smaller than $0.2 \mathrm{psu}$ in absolute value and antisymmetric with respect to the subsatellite track, resulting from the fact that the Faraday rotation varies within the FOV [Fig. 11(a)]. This antisymmetry disappears when the TEC error is increased to $10 \mathrm{TECu}$ (not shown). The retrieved SSS appears unbiased in Table VII because the averaging results in a compensation of biases of opposite signs. Biases on the prior TEC ( -5 and $-10 \mathrm{TECu}$ ) are partly corrected during the retrieval, as the biases on the retrieved TEC amount to about -1 and $-1.5 \mathrm{TECu}$. In ST1 mode, biases on the prior TEC have no effect on the retrieved SSS, showing that the pseudofirst Stokes parameter is insensitive to TEC [Fig. 11(b)].

The SSS biases resulting from the SST biases remain smaller than 0.3 psu in absolute value (Fig. 11). The retrieval does not improve the SST, as the biases on the retrieved SST remain equal to $-1{ }^{\circ} \mathrm{C}$ and $-2{ }^{\circ} \mathrm{C}$ (Table VII). The sensitivity to the SST bias depends on SST range since the sensitivity of $\mathrm{Tb}$ to SST depends on the SST. At the center of the swath, maximum 
(a) High SSS/SST

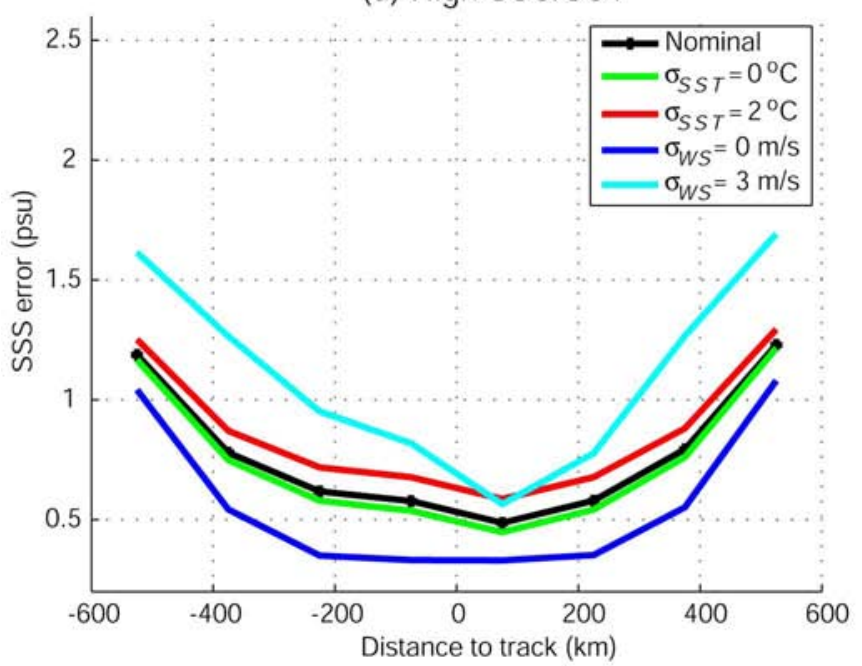

(c) High WS

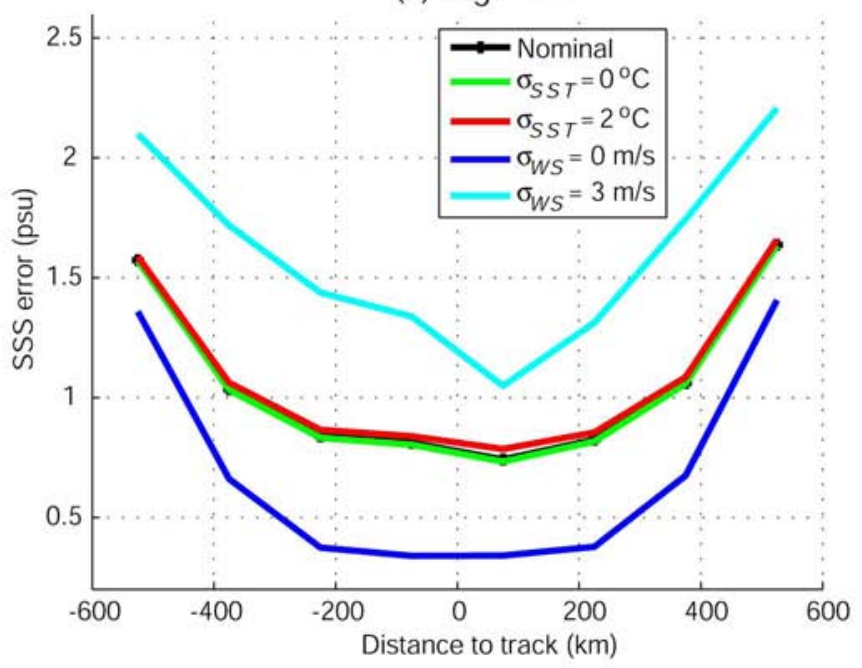

(b) Low SSS/SST

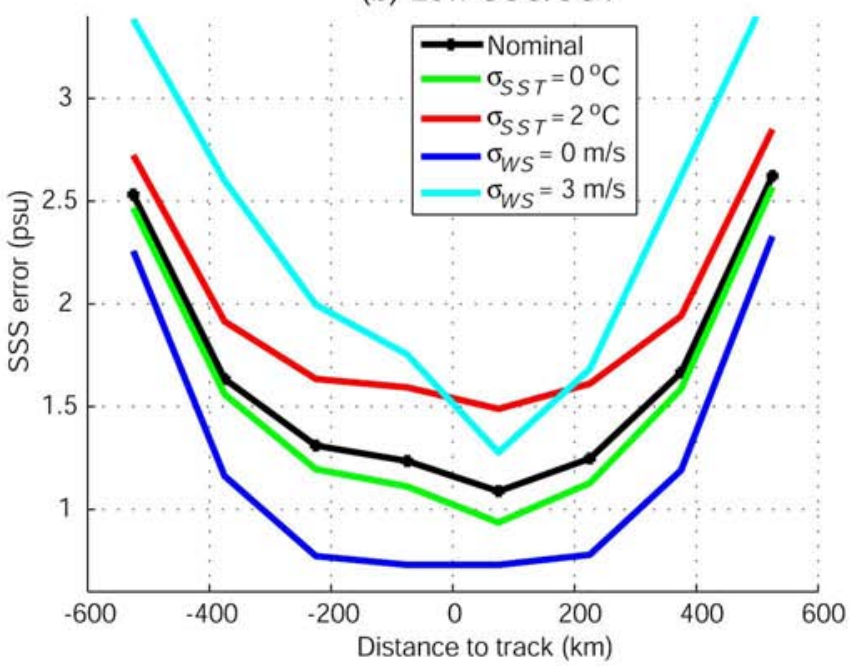

(d) Low WS

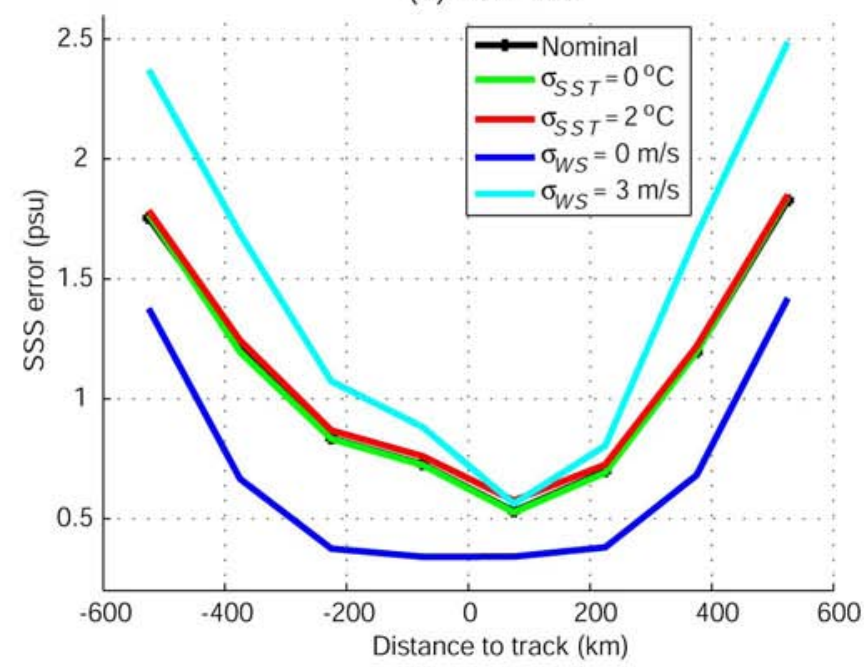

Fig. 8. SSS error as a function of distance to track for model 1 in DP mode: (a) for SSS $=38$ psu and SST $=25^{\circ} \mathrm{C}$, (b) for SSS $=33$ psu and SST $=5{ }^{\circ} \mathrm{C}$ (in both cases, WS $=7 \mathrm{~m} \cdot \mathrm{s}^{-1}$ ), (c) for WS $=15 \mathrm{~m} \cdot \mathrm{s}^{-1}$, and (d) for WS $=3 \mathrm{~m} \cdot \mathrm{s}^{-1}$ (in both cases, SSS $=35$ psu and SST $=15^{\circ} \mathrm{C}$ ).

SSS biases obtained at $5{ }^{\circ} \mathrm{C}, 15{ }^{\circ} \mathrm{C}$, and $25{ }^{\circ} \mathrm{C}$ for $B_{\mathrm{SST}}=$ $-2^{\circ} \mathrm{C}$ amount to $-1.0,-0.3$, and 0.3 psu, respectively (Fig. 12). The smallest SSS bias value is obtained at $15{ }^{\circ} \mathrm{C}$, where sensitivity of $\mathrm{Tb}$ to SST is low (about $-0.04 \mathrm{~K} /{ }^{\circ} \mathrm{C}$ at $35 \mathrm{psu}$ ).

\section{Influence of Sky Radiation}

In order to evaluate the influence of the downwelling sky radiation on the quality of the retrieved SSS, simulations are performed on a fraction of a descending orbit in the North Pacific (Fig. 13) over a homogeneous scene (SSS $=35$ psu, $\mathrm{SST}=15^{\circ} \mathrm{C}$, and WS $=7 \mathrm{~m} \cdot \mathrm{s}^{-1}$ ). The forward model used to simulate the sky radiation contribution to the "measured" Tbs takes into account the rough sea surface scattering effect, using bistatic scattering coefficients [24], [46] (denoted "GN2 method"). Two retrievals are performed, each using a different method in the inverse model to correct for the sky radiation.

1) The GN2 method.

2) A simplified method (denoted "GN1 method"), where the sky radiation is assumed homogeneous, and its intensity is equal to the sky radiation intensity in the specular direction integrated over the SMOS synthetic antenna directional gain (about $2^{\circ}$ angular width). The reflectivity at polarization $p$, i.e., $R_{p}$, is given by

$$
R_{p}=1-\frac{\mathrm{Tb}_{p}}{\mathrm{SST}}
$$

In order to compare the sky contributions computed with the GN1 and the GN2 methods, we compute for each grid point the maximum, minimum, and median sky contributions. The maximum reflected celestial sky radiation computed with 


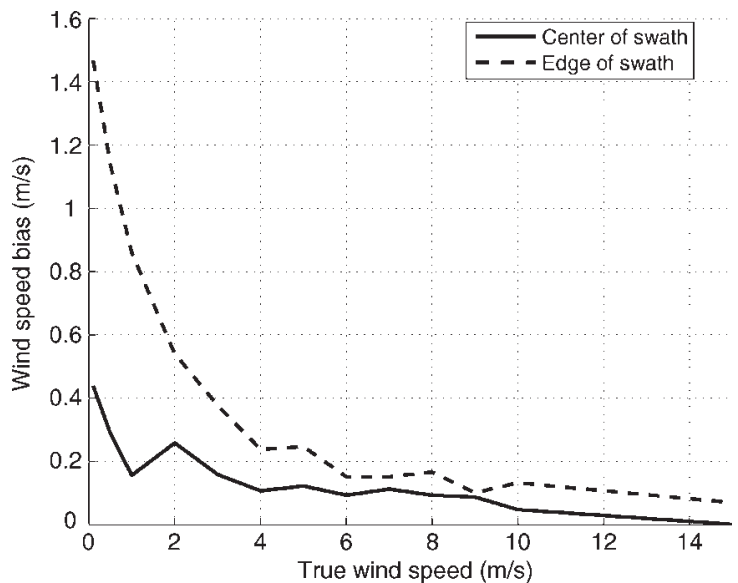

Fig. 9. WS bias as a function of true WS when we retrieve the wind components with model 1 (solid line) at the center of the swath and (dashed line) at the edge.

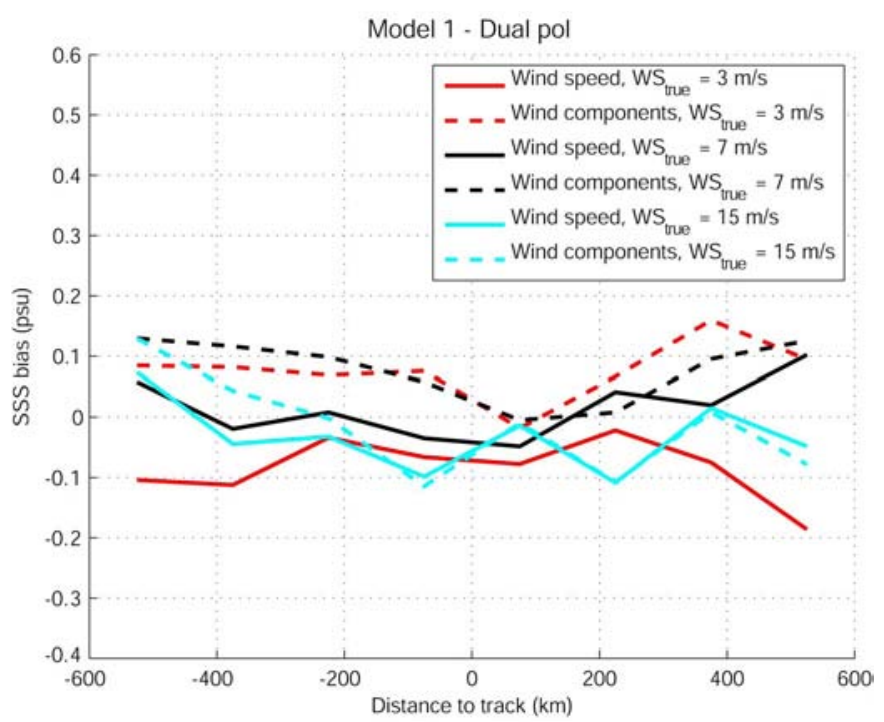

Fig. 10. SSS bias as a function of distance to track for different WSs when the (solid lines) wind components or the (dashed lines) WS is retrieved with model 1.

the GN1 method exhibits strong variations. The first Stokes parameter I ranges from 4.6 to $8.4 \mathrm{~K}$ (Fig. 14, top left). These variations are mostly due to the variations in the incident radiation, as the reflectivity of $I$ is weakly sensitive to changes in incidence angle within the FOV. The maximum scattered sky radiation computed with the GN2 method varies less, with I ranging from 4.6 to $7 \mathrm{~K}$. This is due to the angular spreading of the bright sources by surface roughness, as the bistatic scattering coefficients must be integrated over a solid angle of $40^{\circ}$ angular width about the specular direction to account for $90 \%$ of the reflectivity [46]. The minimum reflected sky radiations show similar behavior for both the GN1 and GN2 methods (Fig. 14, bottom left) because the roughness impact is smaller for cold sources and homogeneous regions of the sky. The $0.5-\mathrm{K}$ variation at $\pm 350 \mathrm{~km}$ from the satellite track corresponds to a change of incidence-angle range (from $25^{\circ}-60^{\circ}$ at $\pm 300 \mathrm{~km}$ to $40^{\circ}-45^{\circ}$ at $\pm 500 \mathrm{~km}$ ), leading to different regions of the sky seen in the specular direction. The stronger GN2
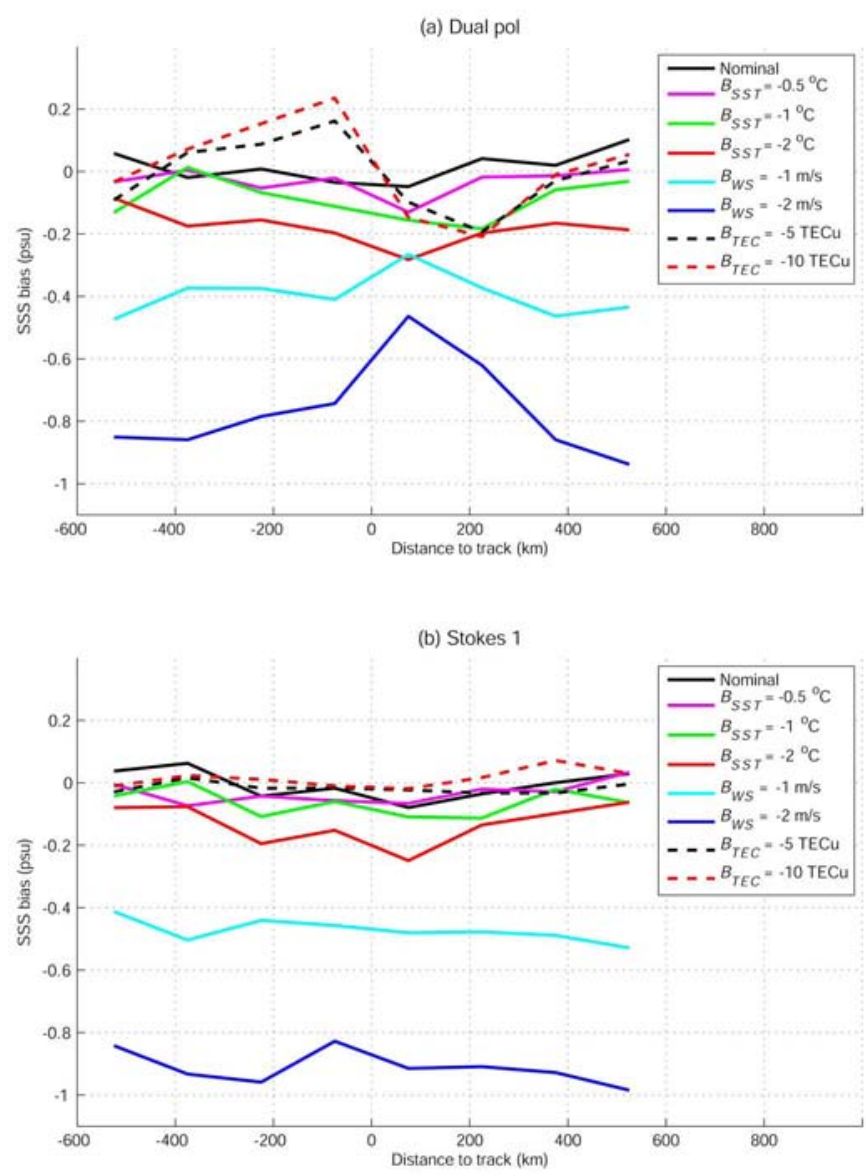

Fig. 11. SSS bias as a function of distance to track for model 1 (a) in DP mode and (b) in ST1 mode for different biases on SST, WS, and TEC.

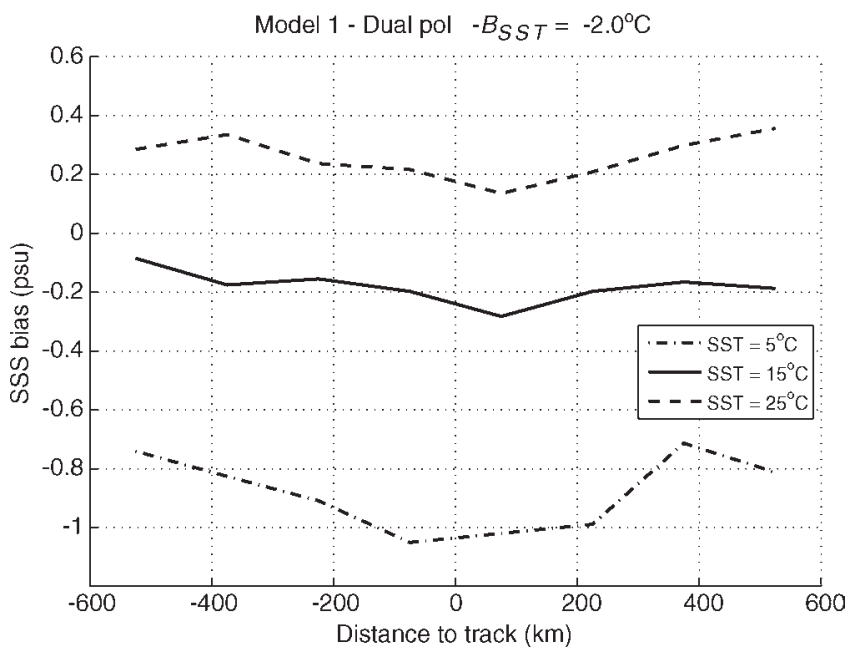

Fig. 12. SSS bias for $B_{\mathrm{SST}}=-2{ }^{\circ} \mathrm{C}$ at $5{ }^{\circ} \mathrm{C}, 15{ }^{\circ} \mathrm{C}$, and $25^{\circ} \mathrm{C}$ for model 1 in DP mode.

signal between 400 and $600 \mathrm{~km}$ is caused by bright sources within the galactic plane entering the solid angle over which the incident celestial radiation is integrated. The median reflected sky radiation shows similar trends for both methods, except at $500 \mathrm{~km}$ from the track, where the GN1 signal is up to $0.5 \mathrm{~K}$ stronger than the GN2 signal (Fig. 14, top right). This creates a 0.2 -psu bias on the SSS retrieved at $500 \mathrm{~km}$ from the track 
with the GN1 method (Fig. 14, bottom right), whereas the bias remains smaller than 0.1 psu between -600 and $300 \mathrm{~km}$. As expected, the SSS bias obtained with the GN2 method is always smaller than $0.1 \mathrm{psu}$ since in these simulations, the GN2 model is implicitly assumed to be perfect.

\section{CONCLUSION}

A prototype processor has been developed to process the SMOS L1C data (reconstructed Tbs in the antenna polarization basis). Outside of one short satellite mission in the 1970s (Skylab) and a few aircraft campaigns, there have been few attempts to retrieve salinity from the L-band radiometric measurements. Therefore, the L2SPP described here has been designed to be easily reconfigured, and it can accommodate alternative forward model components that may be developed after launch. As many of the forward model components require computationally expensive calculations, these model components are implemented in the L2SPP with the help of lookup tables, which also facilitates modification after launch. The inversion is accomplished in the antenna polarization basis. It has the distinct advantage of avoiding potential problems arising from attempting to compute the surface basis Tb components $T_{\mathrm{v}}$ and $T_{\mathrm{h}}$ from nonsimultaneous measurements of the $\mathrm{Tb}$ components in the antenna polarization basis $A_{x}$ and $A_{y}$. Another key advantage of retrieval in the antenna polarization basis is that, in this basis, the measurement errors are uncorrelated. A key product of the inversion algorithm is an estimate of the uncertainty on the retrieved salinity, which is a function of the uncertainties on the reconstructed Tbs, the auxiliary geophysical parameters, and the uncertainties in the forward model components. This uncertainty estimate may be important for data assimilation techniques that typically require such uncertainty estimates. The main drawback of the algorithm is that it is very sensitive to systematic errors (biases) on the reconstructed Tbs, the auxiliary parameters, and the forward models. The accuracy of estimators will depend on the overall reliability of radiometric measurements, of auxiliary data, and of forward models used in the retrieval algorithm. If the dependence of the measured Tbs upon the auxiliary data were linear and identical to that assumed in generating the simulated data, and if the measured Tbs and auxiliary parameters were bias free with a random noise, then the estimator for SSS would be bias free, and the theoretical estimates for uncertainties would be correctly estimated. However, the forward models used in the retrieval are both slightly nonlinear and subject to systematic errors. Hence, one may expect retrieval biases as well as underestimation of the theoretically estimated retrieval uncertainties. The objectives of the $\mathrm{Cal} / \mathrm{Val}$ phase are to find the most suitable auxiliary parameters for salinity retrieval (i.e., those that result in minimum bias) and to minimize the forward model and auxiliary parameter biases. In addition, a pseudocardioid model [66] is being implemented in the L2SPP. It will retrieve a single parameter that synthesizes the available information about surface dielectric characteristics. This avoids modeling the relationship between the geophysical parameters and the surface dielectric properties. The retrieval of this parameter over the ocean could be used to detect the presence of ice and to detect the flaws in reconstructed Tbs, in forward emissivity models, or in auxiliary parameters.

The results of idealized tests conducted over homogeneous scenes with the SMOS L2SPP are in good agreement with the results obtained in previous studies [6], [12]. In the idealized configurations examined here (i.e., homogeneous scenes and no flagged measurements), roughness is the main sea surface signal contaminating the SSS retrieval. The three rough surface emissivity models considered here show similar performance. For all three models and all test conditions considered here, the error on the retrieved SSS depends strongly on the location within the swath. In the case of the reference scene with nominal retrieval conditions, the errors range from $0.5 \mathrm{psu}$ at the center of the swath to $1.7 \mathrm{psu}$ at the edge. The DP mode is more robust than the ST1 mode in the presence of WS biases. For a WS bias of $-1 \mathrm{~m} \cdot \mathrm{s}^{-1}$, the corresponding SSS bias at the center of the swath is -0.3 psu in DP mode, whereas it is $-0.5 \mathrm{psu}$ in ST1 mode. The retrieval method implicitly assumes that the WS error is Gaussian distributed, which is not strictly correct. Therefore, we tested the use of wind components rather than the WS in the retrieval procedure. However, in this more realistic case, the positivity of WS creates an SSS bias at low WSs $\left(0.1 \mathrm{psu}\right.$ at $\left.3 \mathrm{~m} \cdot \mathrm{s}^{-1}\right)$. At $15{ }^{\circ} \mathrm{C}$, the retrieved SSS is weakly sensitive to the SST biases, with the SSS bias always smaller than $0.3 \mathrm{psu}$ for SST biases ranging from $-0.5{ }^{\circ} \mathrm{C}$ to $-2{ }^{\circ} \mathrm{C}$. In DP mode, the TEC biases result in SSS biases smaller than 0.2 psu. The ST1 mode is insensitive to TEC. Failure to fully account for the sea surface-roughness scattering effects in the computation of sky radiation contribution leads to an SSS bias smaller than 0.2 psu in the selected configuration, i.e., a descending orbit over the Northern Pacific in February. Larger (lower) biases are expected when the sky region specularly reflected on the rough sea surface is located closer (further) to the galactic plane. Larger biases can also be found in unfavorable seasonal conditions such as a descending orbit in September [24].

To achieve a SSS bias that is smaller than $0.2 \mathrm{psu}$, there is a need to do the following: 1) to correct for biases at low WS, and 2) to keep the bias on the mean WS (average over $200 \times 200 \mathrm{~km}$ and ten days) smaller than $0.5 \mathrm{~m} / \mathrm{s}$ [6]. The results given in Section III are for instantaneous SSS. In an optimistic case (i.e., random errors), when averaging temporally and/or spatially the retrieved SSS, its error would ideally decrease as $1 / \sqrt{N}$, where $N$ is the number of independent measurements. For example, with a mean spatial resolution of the SMOS measurements of about $40 \mathrm{~km}$, the number of independent measurements within a $200 \times 200 \mathrm{~km}$ box amounts to 25 . At midlatitudes, there are six satellite overpasses in ten days (ascending and descending). Hence, averaging over $200 \times 200 \mathrm{~km}$ and ten days would result in an error divided by 12 . The prototype is being carefully tested and corrected before launch through dedicated simulations, and it is anticipated that it will be modified and improved once SMOS is in orbit and real data become available. An alternative algorithm, based on the neural network philosophy, will also be developed and implemented after launch as an alternative to the approach described here. The quality of the algorithm will be assessed after the SMOS launch, based on comparison between SMOS retrieved SSS, wind and SST, and in situ measured 

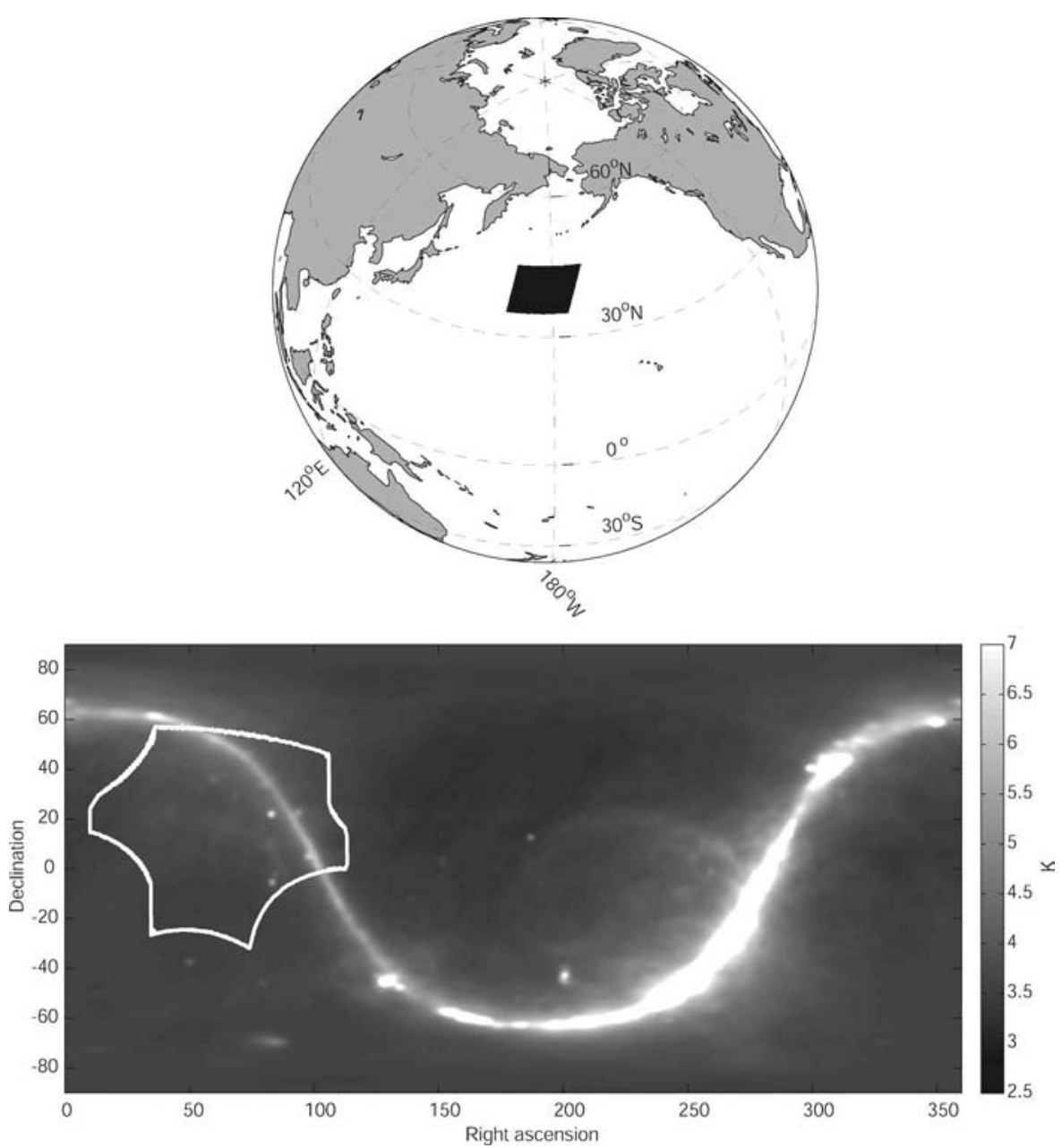

Fig. 13. Location of the fraction of the (top, in black) selected descending orbit and of the corresponding sky region specularly reflected on the rough sea surface and integrated over the (bottom, white contour) SMOS synthetic antenna directional gain. The date of simulation is February $23,2007$.

parameters. Validation of the forward models using airborne measurements [67], [68] is an ongoing process.

\section{APPENDIX A}

\section{ERRORS AND BIASES ON WS AND WIND DIRECTION}

\section{INDUCED BY GAUSSIAN NOISE ON WIND COMPONENTS}

The objective of this appendix is to quantify the WS errors and biases and the wind direction errors induced by Gaussian random noise added to wind components.

We use the following notations.

$\vec{U} \quad$ True wind vector.

$U$ True WS (module of wind vector)

$\theta \quad$ Wind direction (wind direction is counted clockwise with $\theta=0$ indicating a northward wind).

$u, \nu \quad$ Zonal and meridian components of $\vec{U}$.

By definition

$$
\begin{aligned}
U & =\sqrt{u^{2}+\nu^{2}} \\
\theta & =\arctan (u / \nu) \\
u & =U \sin (\theta) \\
\nu & =U \cos (\theta) .
\end{aligned}
$$

Assuming an isotropic error on $\vec{U}$, we define

$$
\begin{aligned}
& u^{\prime}=u+\varepsilon_{u} \\
& \nu^{\prime}=\nu+\varepsilon_{\nu}
\end{aligned}
$$

where $u^{\prime}$ and $\nu^{\prime}$ are the noisy wind components, and $\varepsilon_{u}$ and $\varepsilon_{\nu}$ are the centered randomly distributed errors having the same standard deviation $\sigma$. Thence, the joint density function of $\varepsilon_{u}$ and $\varepsilon_{\nu}$, i.e., $f\left(\varepsilon_{u}, \varepsilon_{\nu}\right)$, is [69]

$$
\begin{aligned}
f\left(\varepsilon_{u}, \varepsilon_{\nu}\right) & =\frac{1}{2 \pi \sigma^{2}} e^{-\left[\varepsilon_{u}^{2}+\varepsilon_{\nu}^{2}\right] / 2 \sigma^{2}} \\
f\left(u^{\prime}, \nu^{\prime}\right) & =\frac{1}{2 \pi \sigma^{2}} e^{-\left[\left(u^{\prime}-u\right)^{2}+\left(\nu^{\prime}-\nu\right)^{2}\right] / 2 \sigma^{2}} .
\end{aligned}
$$

We also define the noisy WS $U^{\prime}$ and direction $\theta^{\prime}$ as

$$
\begin{aligned}
& u^{\prime}=U^{\prime} \cos \left(\theta^{\prime}\right) \\
& \nu^{\prime}=U^{\prime} \sin \left(\theta^{\prime}\right) .
\end{aligned}
$$



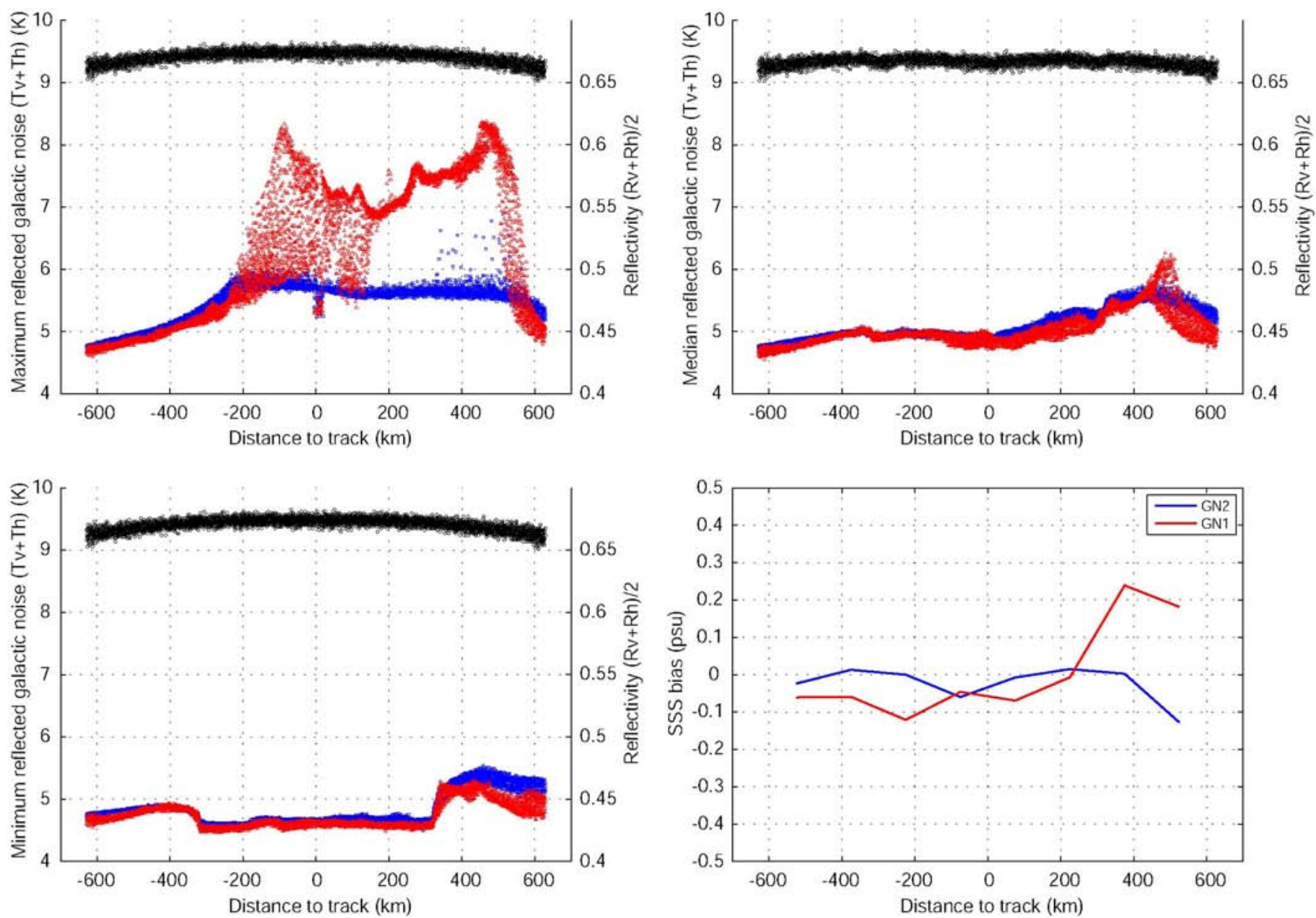

Fig. 14. (Top left) Maximum, (bottom left) minimum, and (top right) median sky radiations scattered by the rough sea surface for each grid point as a function of the distance track. These quantities are computed over all the measurements available for the grid point considered. The sky contribution is computed with (GN1, red triangles) a simplified and (GN2, blue squares) a realistic rough sea surface scattering model in ST1 $\left(T_{\mathrm{v}}+T_{\mathrm{h}}\right)$. The reflectivity $\left(R_{\mathrm{V}}+R_{\mathrm{h}}\right)$ is plotted in black. The (bottom right) SSS bias is obtained with the sky radiation simulated in the inverse model using the (blue line) GN2 method and the (red line) GN1 method. The forward model uses the realistic rough sea surface scattering model (GN2) to compute the sky radiation contribution. The simulations have been performed for a homogeneous scene ( $\mathrm{SSS}=35 \mathrm{psu}, \mathrm{SST}=15^{\circ} \mathrm{C}$, and WS $\left.=7 \mathrm{~m} \cdot \mathrm{s}^{-1}\right)$.

A classical change of variables from $\left(u^{\prime}, \nu^{\prime}\right)$ to $\left(U^{\prime}, \theta^{\prime}\right)$ gives Using (A1), (A3), and (A4)

$$
d u^{\prime} d \nu^{\prime}=U^{\prime} d U^{\prime} d \theta^{\prime}
$$

It follows that the density function of $U^{\prime}$, i.e., $f_{U}$, can be expressed as

$$
\begin{aligned}
f_{U}\left(U^{\prime}\right) d U^{\prime} & =\frac{1}{2 \pi \sigma^{2}} \\
& \times \int_{0}^{2 \pi} e^{-\left[\left(U^{\prime} \cos \left(\theta^{\prime}\right)-u\right)^{2}+\left(U^{\prime} \sin \left(\theta^{\prime}\right)-\nu\right)^{2}\right] / 2 \sigma^{2}} U^{\prime} d \theta^{\prime} d U^{\prime} .
\end{aligned}
$$

$$
f_{U}\left(U^{\prime}\right)=\frac{U^{\prime}}{2 \pi \sigma^{2}} e^{-\left(U^{\prime 2}+U^{2}\right) / 2 \sigma^{2}} \int_{0}^{2 \pi} e^{\left[U U^{\prime} \cos \left(\theta^{\prime}-\theta\right)\right] / \sigma^{2}} d \theta^{\prime}
$$

This yields

$$
f_{U}\left(U^{\prime}\right)=\frac{U^{\prime}}{\sigma^{2}} I_{0}\left(U U^{\prime} / \sigma^{2}\right) e^{-\left(U^{\prime 2}+U^{2}\right) / 2 \sigma^{2}}
$$

where $I_{0}(x)=(1 / 2 \pi) \int_{0}^{2 \pi} e^{\left[x \cos \left(\theta^{\prime}\right)\right]} d \theta^{\prime}$ is the modified Bessel function.

The density function of wind direction can be deduced

Hence as well

$$
\begin{aligned}
f_{U}\left(U^{\prime}\right)=\frac{U^{\prime}}{2 \pi \sigma^{2}} e^{-\left(U^{\prime 2}+u^{2}+\nu^{2}\right) / 2 \sigma^{2}} & \\
& \times \int_{0}^{2 \pi} e^{\left[u U^{\prime} \cos \left(\theta^{\prime}\right)+\nu U^{\prime} \sin \left(\theta^{\prime}\right)\right] / \sigma^{2}} d \theta^{\prime} .
\end{aligned}
$$

$$
\begin{aligned}
f_{\theta}\left(\theta^{\prime}\right) d \theta^{\prime} & =\frac{1}{2 \pi \sigma^{2}} \\
& \times \int_{0}^{\infty} e^{-\left[\left(U^{\prime} \cos \left(\theta^{\prime}\right)-u\right)^{2}+\left(U^{\prime} \sin \left(\theta^{\prime}\right)-\nu\right)^{2}\right] / 2 \sigma^{2}} U^{\prime} d U^{\prime} d \theta^{\prime} .
\end{aligned}
$$



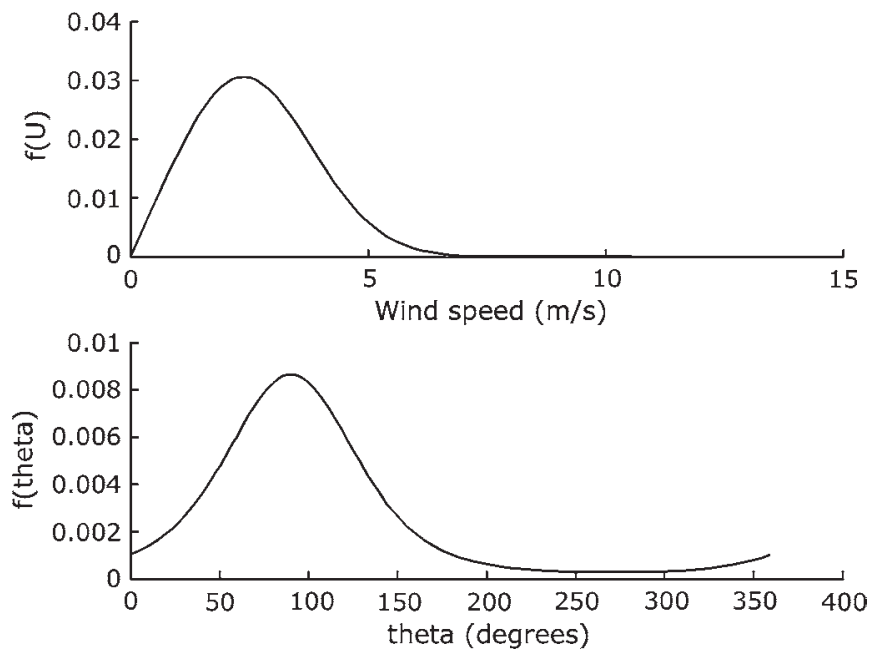

Fig. 15. Density function of (top) WS and (bottom) wind direction (WS: $2 \mathrm{~m} \cdot \mathrm{s}^{-1}$; wind direction: $90^{\circ}$; and error on wind components: $1.5 \mathrm{~m} \cdot \mathrm{s}^{-1}$ ).

Hence

$$
\begin{aligned}
& f_{\theta}\left(\theta^{\prime}\right)=\frac{1}{2 \pi \sigma^{2}} \int_{0}^{\infty} e^{-\left(U^{\prime 2}+U^{2}\right) / 2 \sigma^{2}} e^{\left[U U^{\prime} \cos \left(\theta-\theta^{\prime}\right)\right] / \sigma^{2}} U^{\prime} d U^{\prime} \\
& f_{\theta}\left(\theta^{\prime}\right)=\frac{e^{-U^{2} / 2 \sigma^{2}}}{2 \pi \sigma^{2}} \int_{0}^{\infty} e^{-\left(U^{\prime 2}-2 U U^{\prime} \cos \left(\theta-\theta^{\prime}\right)\right) / 2 \sigma^{2}} U^{\prime} d U^{\prime} .
\end{aligned}
$$

That yields

$$
\begin{aligned}
f_{\theta}\left(\theta^{\prime}\right) & =\frac{e^{-U^{2} / 2 \sigma^{2}}}{2 \pi}+\frac{U^{\prime} \cos \left(\theta-\theta^{\prime}\right)}{\sigma \sqrt{8 \pi}} \\
& \times e^{-\left(U^{\prime 2} \sin ^{2}\left(\theta-\theta^{\prime}\right)\right) / 2 \sigma^{2}} \operatorname{erfc}\left[\frac{-U^{\prime} \cos \left(\theta-\theta^{\prime}\right)}{\sigma \sqrt{2}}\right]
\end{aligned}
$$

where erfc is the error function defined from an integral of a Gaussian law.

Note that this density function is periodic but defined uniquely on the support $\left[\begin{array}{ll}0 & 2 \pi\end{array}\right.$ [ to avoid both redundancy of information and a normalization over $]-\infty ;+\infty[$. The density functions of $U$ and $\theta$ are shown in Fig. 15 for $U=2 \mathrm{~m} \cdot \mathrm{s}^{-1}$, $\theta=90^{\circ}$, and $\sigma=1.5 \mathrm{~m} \cdot \mathrm{s}^{-1}$.

When $U=0, f_{U}\left(U^{\prime}\right)$ is a Rayleigh density function and

$$
\begin{aligned}
\left\langle U^{\prime}\right\rangle_{U=0} & =\sigma \sqrt{\frac{\pi}{2}} \\
\operatorname{std}\left(U^{\prime}\right)_{U=0} & =\sigma \sqrt{2-\frac{\pi}{2}}
\end{aligned}
$$

Using normalized variables

$$
\begin{aligned}
U_{\mathrm{n}} & =U / \sigma \\
U_{\mathrm{n}}^{\prime} & =U^{\prime} / \sigma \\
d U_{\mathrm{n}}^{\prime} & =d U^{\prime} / \sigma \\
f_{U}\left(U^{\prime}\right) & =\frac{U_{\mathrm{n}}^{\prime}}{\sigma} I_{0}\left(U_{\mathrm{n}} U_{\mathrm{n}}^{\prime}\right) e^{-\left(U_{\mathrm{n}}^{\prime 2}+U_{\mathrm{n}}^{2}\right) / 2} .
\end{aligned}
$$

The average of $U^{\prime}$, i.e., $\left\langle U^{\prime}\right\rangle$, and the standard deviation of $U^{\prime}$, i.e., $\operatorname{std}\left(U^{\prime}\right)$, are deduced as

$$
\begin{aligned}
\left\langle U^{\prime}\right\rangle & =\int_{0}^{\infty} U^{\prime} f_{U}\left(U^{\prime}\right) d U^{\prime} \\
& =\sigma \int_{0}^{\infty} U_{\mathrm{n}}^{\prime 2} I_{0}\left(U_{\mathrm{n}} U_{\mathrm{n}}^{\prime}\right) e^{-\left(U_{\mathrm{n}}^{\prime 2}+U_{\mathrm{n}}^{2}\right) / 2} d U_{\mathrm{n}}^{\prime}
\end{aligned}
$$

i.e.,

$$
\left\langle U^{\prime}\right\rangle / \sigma=F_{1}\left(U_{\mathrm{n}}\right)
$$

and

$$
\begin{aligned}
\operatorname{std}\left(U^{\prime}\right)^{2} & =\int_{0}^{\infty}\left(U^{\prime}-\left\langle U^{\prime}\right\rangle\right)^{2} f_{U}\left(U^{\prime}\right) d U^{\prime}=\left\langle U^{\prime 2}\right\rangle-\left\langle U^{\prime}\right\rangle^{2} \\
& =\sigma^{2}\left(\int_{0}^{\infty} U_{\mathrm{n}}^{\prime 3} I_{0}\left(U_{\mathrm{n}} U_{\mathrm{n}}^{\prime}\right)\right.
\end{aligned}
$$

i.e.,

$$
\operatorname{std}\left(U^{\prime}\right) / \sigma=F_{2}\left(U_{\mathrm{n}}\right)
$$

where $F_{1}$ and $F_{2}$ are uniquely dependent upon the normalized variable $U_{\mathrm{n}}$.

The variations of $F_{1}\left(U_{\mathrm{n}}\right)-U_{\mathrm{n}}$ (i.e., the normalized WS bias induced by the noise on the wind components) and $F_{2}$ (i.e., the normalized standard deviation of the WS error) are shown in Fig. 16, as well as the bias and the error obtained for windcomponent errors of $1.5 \mathrm{~m} \cdot \mathrm{s}^{-1}$.

The density function of wind direction can also be expressed as a function of normalized variables

$$
f_{\theta}\left(\theta^{\prime}\right)=\frac{e^{-U_{\mathrm{n}}^{2} / 2}}{2 \pi} \int_{0}^{\infty} e^{-\left(U_{\mathrm{n}}^{\prime 2}-2 U_{\mathrm{n}} U_{\mathrm{n}}^{\prime} \cos \left(\theta-\theta^{\prime}\right)\right) / 2} U_{\mathrm{n}}^{\prime} d U_{\mathrm{n}}^{\prime}
$$

so that the error on wind direction is only dependent on $U / \sigma$.

The error on wind direction as a function of $U / \sigma$ and in the particular case $\sigma=1.5 \mathrm{~m} \cdot \mathrm{s}^{-1}$ as a function of $U$ are shown in Fig. 17. 

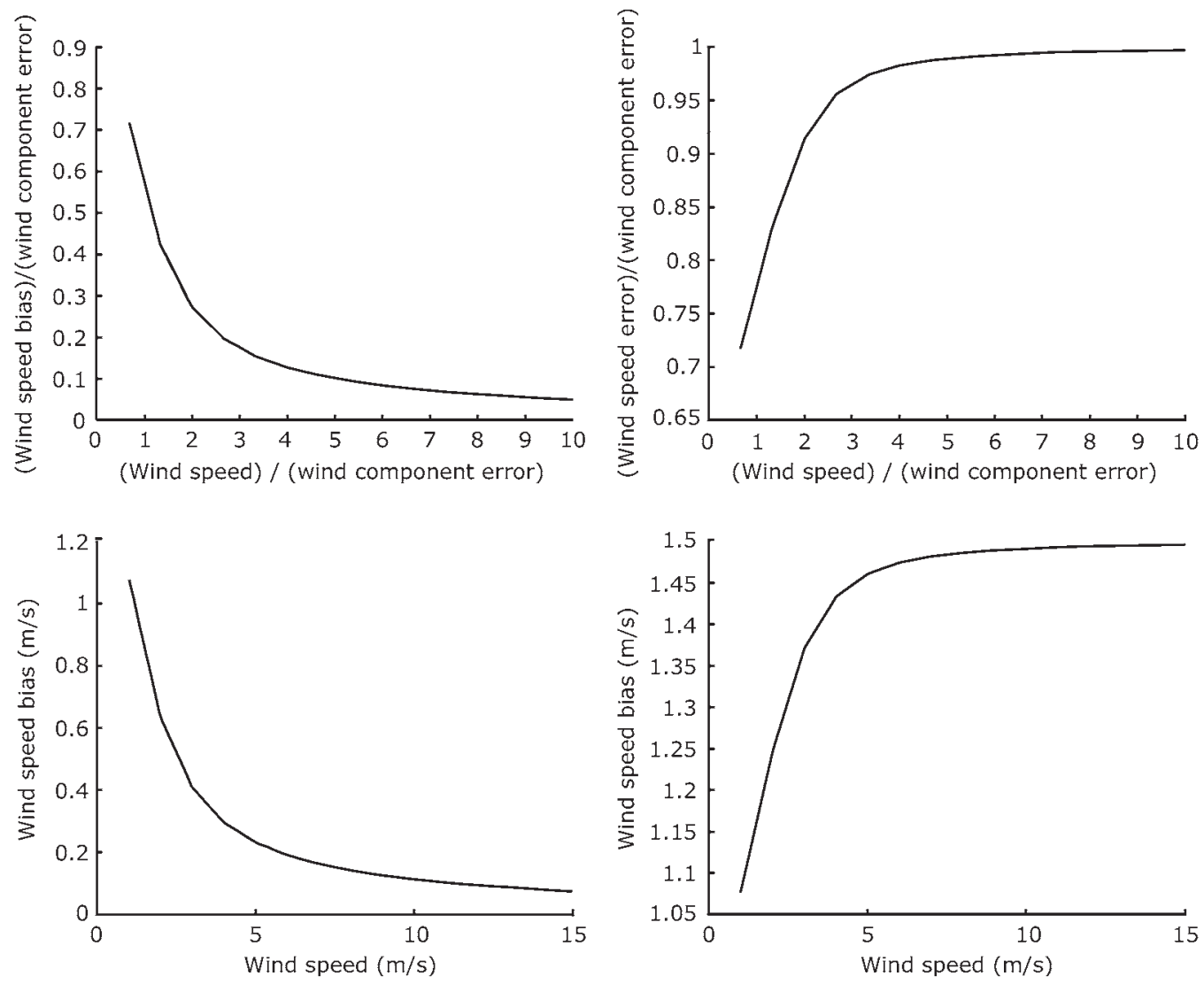

Fig. 16. (Top left) $\left(\left\langle U^{\prime}\right\rangle-U\right) / \sigma$ as a function of $U / \sigma$. (Top right) $\operatorname{std}\left(U^{\prime}\right) / \sigma$ as a function of $U / \sigma$. (Bottom left) $\left\langle U^{\prime}\right\rangle-U$ (in meters per second) as a function of $U$ (in meters per second) with $\sigma=1.5 \mathrm{~m} \cdot \mathrm{s}^{-1}$. (Bottom right) $\operatorname{std}\left(U^{\prime}\right)$ (in meters per second) as a function of $U$ (in meters per second) with $\sigma=1.5 \mathrm{~m} \cdot \mathrm{s}^{-1}$.
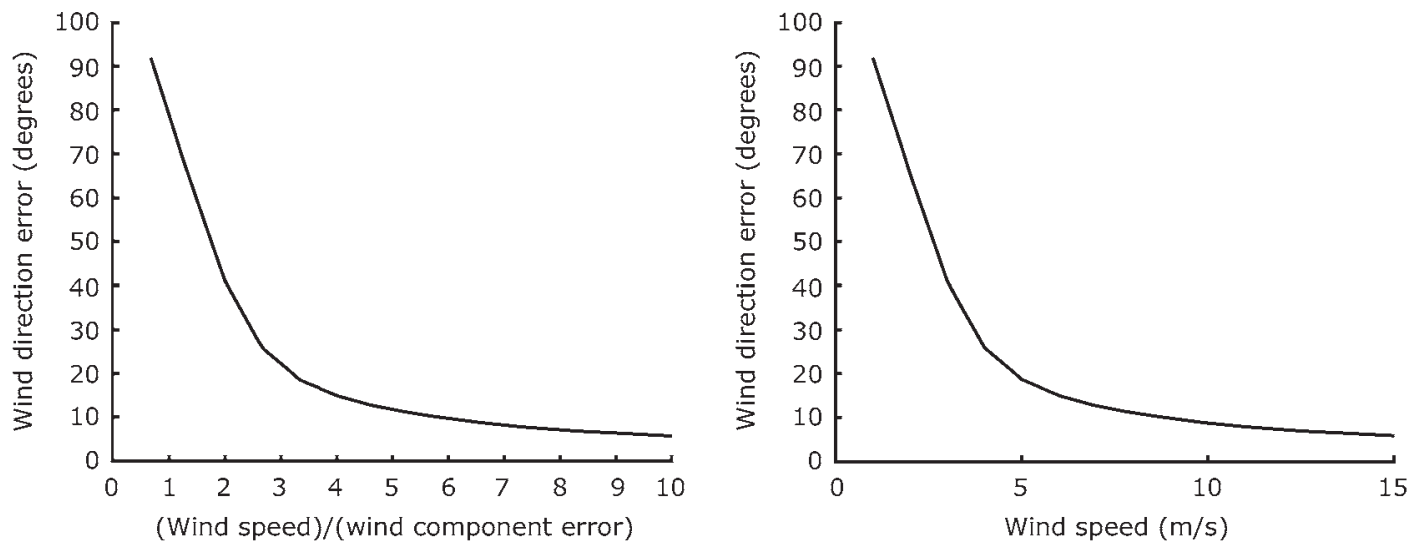

Fig. 17. Error on wind direction as (left) a function of normalized WS and as (right) a function of WS for $1.5-\mathrm{m} \cdot \mathrm{s}^{-1}$ error on wind components.

\section{APPENDIX B}

\section{Geometrical Projection of Model ERror FROM EARTH REFERENCE FRAME TO ANTENNA REFERENCE FrAME}

For a single measurement, the variance-covariance matrix for $T_{\mathrm{b}}^{\bmod }\left(C_{\mathrm{Earth}}^{\bmod }\right)$ is diagonal in the Earth reference frame

$C_{\text {Earth }}^{\bmod }=\left(\begin{array}{cccc}\sigma_{\text {Th_model }}^{2} & 0 & 0 & 0 \\ 0 & \sigma_{\mathrm{Tv} \_ \text {model }}^{2} & 0 & 0 \\ 0 & 0 & \sigma_{\mathrm{T} 3 \_ \text {model }}^{2} & 0 \\ 0 & 0 & 0 & \sigma_{\mathrm{T} 4 \_ \text {model }}^{2}\end{array}\right)$ where $\sigma_{\mathrm{Th} \_ \text {model }}^{2}, \sigma_{\mathrm{TV} \_ \text {model }}^{2}, \sigma_{\mathrm{T} 3 \_ \text {model }}^{2}$, and $\sigma_{\mathrm{T} 4 \_ \text {model }}^{2}$ are the variances of the components $T_{\mathrm{h}}^{\bmod }, T_{\mathrm{v}}^{\bmod }, T_{3}^{\text {mod }}$, and $T_{4}^{\text {mod }}$, respectively, of the Stokes vector $T_{\mathrm{b}}$ mod in the Earth reference frame. The correlations of the model error between different measurements are neglected. Model errors are expected to be significantly lower (about ten times) than measurement errors, so that correlations of the model error between different measurements are expected to be negligible compared with the measurement errors.

The value of the model uncertainty is determined by considering the assumptions and the limitations of each component of the forward model. In the present approach, we assume that 


$$
C_{A}=\left(\begin{array}{cccc}
\sigma_{A x \_ \text {meas }}^{2}+\sigma_{A x \_ \text {model }}^{2} & 0 & 0 & 0 \\
0 & \sigma_{A y \_ \text {meas }}^{2}+\sigma_{A y \_ \text {model }}^{2} & 0 & 0 \\
0 & 0 & \sigma_{A 3 \_ \text {meas }}^{2}+\sigma_{A 3 \_ \text {model }}^{2} & 0 \\
0 & 0 & 0 & \sigma_{A 4 \_ \text {meas }}^{2}+\sigma_{A 4 \_ \text {model }}^{2}
\end{array}\right)
$$

this uncertainty is constant and independent of polarization in the Earth reference frame. In the future, $\sigma_{\mathrm{Tb}}$ _model could be given as an analytical function of auxiliary parameters (SST, WS, etc.), incidence angle, and polarization. Most systematic biases of the modeled $\mathrm{Tb}$ are expected to be determined during the Cal/Val phase, and the models will be corrected accordingly.

The method of transport of the error variances to the antenna reference frame is detailed next. The covariance matrix in the antenna reference frame $\left(C_{\mathrm{Ant}}^{\bmod }\right)$ for $T_{\mathrm{b}}^{\bmod }$ is given in the antenna reference frame by

$$
C_{\mathrm{Ant}}^{\bmod }=(\mathrm{MR} 4) C_{\mathrm{Earth}}^{\bmod }(\mathrm{MR} 4)^{\mathrm{T}}
$$

where (MR4) is the rotation matrix defined in (1), and $\mathrm{T}$ represents the transposition operation.

$C_{\mathrm{Ant}}^{\bmod }$ is then given by

$C_{\mathrm{Ant}}^{\mathrm{mod}}=\left(\begin{array}{cccc}\sigma_{A x \_ \text {model }}^{2} & c_{12} & c_{13} & c_{14} \\ c_{21} & \sigma_{A y \_ \text {model }}^{2} & c_{23} & c_{24} \\ c_{31} & c_{32} & \sigma_{A 3 \_ \text {model }}^{2} & c_{34} \\ c_{41} & c_{42} & c_{43} & \sigma_{A 4 \_ \text {model }}^{2}\end{array}\right)$

with the variances

$$
\begin{aligned}
\sigma_{A x \_ \text {model }}^{2}= & \sigma_{\mathrm{Th} \_ \text {model }}^{2} \cos ^{4}(a)+\sigma_{\mathrm{T} \mathrm{v} \_ \text {model }}^{2} \sin ^{4}(a) \\
& +\sigma_{\mathrm{T} 3 \_ \text {model }}^{2} \cos ^{2}(a) \sin ^{2}(a) \\
\sigma_{A y \_ \text {model }}^{2}= & \sigma_{\mathrm{Th} \_ \text {model }}^{2} \sin ^{4}(a)+\sigma_{\mathrm{T} \mathrm{v} \_ \text {model }}^{2} \cos ^{4}(a) \\
& +\sigma_{\mathrm{T} 3 \_ \text {model }}^{2} \cos ^{2}(a) \sin ^{2}(a) \\
\sigma_{A 3 \_ \text {model }}^{2}= & \left(\sigma_{\mathrm{Th} \_ \text {model }}^{2}+\sigma_{\mathrm{T} \mathrm{v} \_ \text {model }}^{2}\right) \sin ^{2}(2 a) \\
& +\sigma_{\mathrm{T} 3 \_ \text {model }}^{2} \cos ^{2}(2 a) \\
\sigma_{A 4 \_ \text {model }}^{2}= & \sigma_{\mathrm{T} 4 \_m o d e l}^{2}
\end{aligned}
$$

and the covariances

$$
\begin{aligned}
& c_{21}=\left(\sigma_{\text {Th_model }}^{2}+\sigma_{\text {Tv_model }}^{2}-\sigma_{\text {T3_model }}^{2}\right) \cos ^{2}(a) \sin ^{2}(a) \\
& c_{31}=\sigma_{\text {Th_model }}^{2} \cos ^{2}(a) \sin (2 a)-\sigma_{\text {Tv_model }}^{2} \sin ^{2}(a) \sin (2 a) \\
& -\sigma_{\mathrm{T} 3 \_ \text {model }}^{2} \cos (a) \sin (a) \cos (2 a) \\
& c_{41}=0 \quad c_{12}=c_{21} \\
& c_{32}=\sigma_{\text {Th_model }}^{2} \sin ^{2}(a) \sin (2 a)-\sigma_{\text {Tv_model }}^{2} \cos ^{2}(a) \sin (2 a) \\
& +\sigma_{\mathrm{T} 3 \_m o d e l}^{2} \cos (a) \sin (a) \cos (2 a) \\
& c_{42}=0 \quad c_{13}=c_{31} \quad c_{23}=c_{32} \\
& c_{43}=0 \quad c_{14}=0 \quad c_{24}=0 \\
& c_{34}=0 \text {. }
\end{aligned}
$$

Note that this matrix is not diagonal, leading to correlated model errors in the antenna reference frame.

As the measurement error is assumed to be uncorrelated in the antenna reference frame, the covariance matrix for $A^{\text {meas }}\left(C^{\text {meas }}\right)$ is diagonal in the antenna reference frame

$C^{\text {meas }}=\left(\begin{array}{cccc}\sigma_{A x \_ \text {meas }}^{2} & 0 & 0 & 0 \\ 0 & \sigma_{A y \_ \text {meas }}^{2} & 0 & 0 \\ 0 & 0 & \sigma_{A 3 \_ \text {meas }}^{2} & 0 \\ 0 & 0 & 0 & \sigma_{A 4 \_ \text {meas }}^{2}\end{array}\right)$

where $\sigma_{A x \_m e a s}^{2}, \sigma_{A y \_m e a s}^{2}, \sigma_{A 3 \_ \text {meas }}^{2}$, and $\sigma_{A 4 \_ \text {meas }}^{2}$ are the variances of the $A^{\text {meas }}$ components $\left(A_{x}^{\text {meas }}, A_{y}^{\text {meas }}, A_{3}^{\text {meas }}\right.$, and $\left.A_{4}^{\text {meas }}\right)$ in the antenna reference frame. The value of the measurement uncertainty is from the SMOS L1C data product output.

Finally, since errors are assumed to be Gaussian, the variance-covariance matrix of $A$, i.e., $C_{A}$, is given in the antenna reference frame by

$$
C_{A}=C^{\text {meas }}+C_{\mathrm{Ant}}^{\mathrm{mod}} .
$$

For the same reasons as aforementioned, the correlations are neglected, and the $C_{\mathrm{Tb}}$ matrix is assumed to be diagonal, shown at the top of the page. Therefore, $\sigma_{A}^{2}=\sigma_{A}^{2}$ meas $+\sigma_{A}^{2} \_$model.

\section{ACKNOWLEDGMENT}

The authors would like to thank N. Martin for the computing advice.

\section{REFERENCES}

[1] P. Silvestrin, M. Berger, Y. H. Kerr, and J. Font, "ESA's second Earth explorer opportunity mission: The Soil Moisture and Ocean Salinity mission-SMOS," IEEE Geosci. Remote Sens. Newslett., vol. 118, pp. 11-14, 2001

[2] A. Camps and C. T. Swift, "New techniques in microwave radiometry for Earth remote sensing," in Review of Radio Science 1999-2002, W. R. Stone, Ed. Piscataway, NJ: IEEE Press, 2002, pp. 499-518.

[3] Y. H. Kerr, P. Waldteufel, J.-P. Wigneron, J.-M. Martinuzzi, J. Font, and M. Berger, "Soil moisture retrieval from space: The Soil Moisture and Ocean Salinity (SMOS) mission," IEEE Trans. Geosci. Remote Sens., vol. 39, no. 8, pp. 1729-1735, Aug. 2001.

[4] G. S. E. Lagerloef, C. T. Swift, and D. M. Le Vine, "Sea surface salinity: The next remote sensing challenge," Oceanography, vol. 8, no. 2, pp. 44-50, 1995. 
[5] S. H. Yueh, R. West, W. J. Wilson, F. K. Li, E. G. Njoku, and Y. Rahmat-Samii, "Error sources and feasibility for microwave remote sensing of ocean surface salinity," IEEE Trans. Geosci. Remote Sens., vol. 39, no. 5, pp. 1049-1060, May 2001.

[6] J. Boutin, P. Waldteufel, N. Martin, G. Caudal, and E. P. Dinnat, "Surface salinity retrieved from SMOS measurements over the global ocean: Imprecisions due to sea surface roughness and temperature uncertainties," J. Atmos. Ocean. Technol., vol. 21, no. 9, pp. 1432-1447, Sep. 2004.

[7] A. Camps, M. Vall-llosera, L. Batres, F. Torres, N. Duffo, and I. Corbella, "Retrieving sea surface salinity with multiangular L-band brightness temperatures: Improvement by spatio-temporal averaging," Radio Sci., vol. 40, no. 2, pp. 1-13, 2005, DOI: 10.1029/2004RS003040.

[8] J. Font, G. S. E. Lagerloef, D. M. Le Vine, A. Camps, and O. Z. Zanifé, "The determination of surface salinity with the European SMOS space mission," IEEE Trans. Geosci. Remote Sens., vol. 42, no. 10, pp. 21962205, Oct. 2004

[9] C. J. Koblinsky, P. Hildebrand, D. M. Le Vine, F. Pellerano, Y. Chao, W. J. Wilson, S. H. Yueh, and G. S. E. Lagerloef, "Sea surface salinity from space: Science goals and measurement approach," Radio Sci., vol. 38 , no. 4, 8064, 2003, DOI: 10.1029/2001RS002584.

[10] J. Font, J. Boutin, N. Reul, P. Waldteufel, C. Gabarró, S. Zine, and J. Tenerelli, SMOS Sea Surface Salinity Level 2 Algorithm Theoretical Baseline Document-Issue 2, European Space Agency ESTEC Contract 18933/05/NL/FF, 2007

[11] I. Corbella, A. Camps, M. Zapata, F. Marcos, F. Martínez, F. Torres, M. Vall-llosera, N. Duffo, and J. Bará, "End-to-end simulator of two-dimensional interferometric radiometry," Radio Sci., vol. 38, no. 3, 8058, 2003, DOI: 10.1029/2002RS002665.

[12] F. Petitcolin, J. Boutin, J.-L. Vergely, P. Waldteufel, N. Reul, and J. Font, Final Report of the Study 'Soil Moisture Retrieval for SMOS Mission', CCN2 For Sea Surface Salinity Retrieval, European Space Agency ESTEC Contract 16027/02/NL/GS, SMOS-TN-ACR-LOD-006, 2005.

[13] I. Corbella, N. Duffo, M. Vall-llosera, A. Camps, and F. Torres, "The visibility function in interferometric aperture synthesis radiometry," IEEE Trans. Geosci. Remote Sens., vol. 42, no. 8, pp. 1677-1682, Aug. 2004.

[14] E. Anterrieu, P. Waldteufel, and A. Lannes, "Apodization functions for 2-D hexagonally sampled synthetic aperture imaging radiometers," IEEE Trans. Geosci. Remote Sens., vol. 40, no. 12, pp. 2531-2542, Dec. 2002.

[15] A. Camps, I. Corbella, F. Torres, N. Duffo, M. Vall-llosera, and M. Martin-Neira, "The impact of antenna pattern frequency dependence in aperture synthesis microwave radiometers," IEEE Trans. Geosci. Remote Sens., vol. 43, no. 10, pp. 2218-2224, Oct. 2005.

[16] J. P. Snyder, "An equal-area map projection for polyhedral globes," Cartographica, vol. 29, no. 1, pp. 10-21, 1992.

[17] P. Waldteufel and G. Caudal, "About off-axis radiometric polarimetric measurements," IEEE Trans. Geosci. Remote Sens., vol. 40, no. 6, pp. 1435-1439, Jun. 2002.

[18] P. Waldteufel, N. Floury, E. P. Dinnat, and G. Caudal, "Ionospheric effect for L-band 2-D interferometric radiometry," IEEE Trans. Geosci. Remote Sens., vol. 42, no. 1, pp. 105-118, Jan. 2004.

[19] J. P. Claassen and A. K. Fung, "The recovery of polarized apparent temperature distributions of flat scenes from antenna temperature measurements," IEEE Trans. Antennas Propag., vol. AP-22, no. 3, pp. 433442, May 1974

[20] Y. H. Kerr, J. Font, P. Waldteufel, A. Camps, J. Bará, I. Corbella, F. Torres, N. Duffo, M. Vall-llosera, and G. Caudal, "Next generation radiometers: SMOS, a dual pol L-band 2D aperture synthesis radiometer," presented at the IEEE Aerospace Conf., Big Sky, MT, 2000.

[21] A. Camps, I. Corbella, M. Vall-1losera, N. Duffo, F. Torres, R. Villarino, L. Enrique, F. Julbe, J. Font, A. Juliá, C. Gabarró, J. Etcheto, J. Boutin, A. Weill, E. Rubio, V. Caselles, P. Wursteisen, and M. Martín-Neira, "L-band sea surface emissivity: Preliminary results of the WISE-2000 campaign and its applications to salinity retrieval in the SMOS mission," Radio Sci., vol. 38, no. 4, 8071, 2003, DOI: 10.1029/2002RS002629.

[22] S. Zine, J. Boutin, P. Waldteufel, J.-L. Vergely, T. Pellarin, and P. Lazure, "Issues about retrieving sea surface salinity in coastal areas from SMOS data," IEEE Trans. Geosci. Remote Sens., vol. 45, no. 7, pp. 2061-2072, Jul. 2007.

[23] J. Stroeve and W. Meier, Sea Ice Trends and Climatologies From SMMR and SSM/I, vol. 2007. Boulder, CO: Nat. Snow Ice Data Center, 1999. updated 2007, Digital media.

[24] N. Reul, J. Tenerelli, N. Floury, and B. Chapron, "Earth-viewing L-band radiometer sensing of sea surface scattered celestial sky radiation-Part II: Application to SMOS," IEEE Trans. Geosci. Remote Sens., vol. 46, no. 3, pp. 675-688, Mar. 2008.
[25] L. A. Klein and C. T. Swift, "An improved model for the dielectric constant of sea water at microwave frequencies," IEEE Trans. Antennas Propag., vol. AP-25, no. 1, pp. 104-111, Jan. 1977.

[26] E. P. Dinnat, J. Boutin, G. Caudal, and J. Etcheto, "Issues concerning the sea emissivity modeling at L band for retrieving surface salinity," Radio Sci., vol. 38, no. 4, 8060, 2003, DOI:10.1029/2002RS002637.

[27] N. Reul, B. Chapron, S. Mevel, P.-Y. Le Traon, E. Obligis, C. Boone, P. Bahurel, P. Brasseur, C.-E. Testut, B. Tranchant, J. Font, C. Gabarró, M. Srokosz, H. Snaith, C. Gommenginger, A. Camps, M. Vall-llosera, J. Miranda, R. Sabia, O. Germain, F. Soulat, L. Bertino, D. M. Le Vine, and G. S. E. Lagerloef, Synergetic Aspects and Auxiliary Data Concepts for Sea Surface Salinity Measurements From Space, European Space Agency ESTEC Contract 18176/04/NL/CB, Final report, 2006.

[28] S. L. Durden and J. F. Vesecky, "A physical radar cross-section model for a wind-driven sea with swell," IEEE J. Ocean. Eng., vol. OE-10, no. 4, pp. 445-451, Oct. 1985.

[29] F. Wentz, "A two-scale model for foam-free sea microwave brightness temperature," J. Geophys. Res., vol. 80, pp. 3441-3446, 1975.

[30] S. H. Yueh, "Modeling of wind direction signals in polarimetric sea surface brightness temperatures," IEEE Trans. Geosci. Remote Sens., vol. 35, no. 6, pp. 1400-1418, Nov. 1997.

[31] E. P. Dinnat, J. Boutin, G. Caudal, J. Etcheto, and P. Waldteufel, "Influence of sea surface emissivity model parameters in L-band for the estimation of salinity," Int. J. Remote Sens., vol. 23, no. 23, pp. 5117 5122, Dec. 2002

[32] V. G. Irisov, "Small-slope expansion for thermal and reflected radiation from a rough surface," Waves Random Media, vol. 7, no. 1, pp. 1-10, Jan. 1997.

[33] J. T. Johnson and M. Zhang, "Theoretical study of the small slope approximation for ocean polarimetric thermal emission," IEEE Trans. Geosci. Remote Sens., vol. 37, no. 5, pp. 2305-2316, Sep. 1999.

[34] V. N. Kudryavtsev, V. K. Makin, and B. Chapron, "Coupled sea surfaceatmosphere model—Part 2: Spectrum of short wind waves," J. Geophys. Res., vol. 104, no. C4, pp. 7625-7639, 1999.

[35] N. Reul and B. Chapron, "A model of sea foam thickness distribution for passive microwave remote sensing applications," J. Geophys. Res. vol. 108 , no. C10, 3321, 2003, DOI: 10.1029/2003JC001887.

[36] A. Camps, M. Vall-llosera, R. Villarino, N. Reul, B. Chapron, I. Corbella, N. Duffo, F. Torres, J. J. Miranda, R. Sabia, A. Monerris, and R. Rodríguez, "The emissivity of foam-covered water surface at L-band: Theoretical modeling and experimental results from the FROG 2003 field experiment," IEEE Trans. Geosci. Remote Sens., vol. 43, no. 5, pp. 925 937, May 2005

[37] J. Etcheto, E. P. Dinnat, J. Boutin, A. Camps, J. Miller, S. Contardo, J. Wesson, J. Font, and D. G. Long, "Wind speed effect on L-band brightness temperatures inferred from EuroSTARRS and WISE 2001 field experiments," IEEE Trans. Geosci. Remote Sens., vol. 42, no. 10, pp. 2206-2213, Oct. 2004

[38] A. Camps, J. Font, M. Vall-llosera, C. Gabarró, I. Corbella, N. Duffo, F. Torres, S. Blanch, A. Aguasca, R. Villarino, L. Enrique, J. J. Miranda, J. Arenas, A. Juliá, J. Etcheto, V. Caselles, A. Weill, J. Boutin, S. Contardo, R. Niclós, R. Rivas, S. C. Reising, P. Wursteisen, M. Berger, and M. Martín-Neira, "The WISE 2000 and 2001 field experiments in support of the SMOS mission: Sea surface L-band brightness temperature observations and their application to sea surface salinity retrieval," IEEE Trans. Geosci. Remote Sens., vol. 42, no. 4, pp. 804-823, Apr. 2004.

[39] C. Gabarró, J. Font, A. Camps, M. Vall-llosera, and A. Juliá, "A new empirical model of sea surface microwave emissivity for salinity remote sensing," Geophys. Res. Lett., vol. 31, no. 1, pp. L01309-1-L01309-5, 2004, DOI: 10.1029/2003GL018964.

[40] C. Gabarró, J. Font, J. L. Miller, A. Camps, D. Burrage, J. Wesson, and A. R. Piola, "The use of a semi-empirical emissivity model for a rough estimation of sea surface salinity from an airborne microwave radiometer," Sci. Mar., vol. 72, to be published.

[41] "The WAM model—A third generation wave prediction model," J. Phys. Oceanogr., vol. 18, pp. 1775-1810, 1988.

[42] C. Cox and W. Munk, "Statistics of the sea surface derived from sun glitter," J. Mar. Res., vol. 13, pp. 198-227, 1954.

[43] C. T. Swift and R. E. McIntosh, "Considerations for microwave remote sensing of ocean surface salinity," IEEE Trans. Geosci. Remote Sens., vol. GRS-21, no. 4, pp. 480-491, Oct. 1983.

[44] D. M. Le Vine and S. Abraham, "Galactic noise and passive microwave remote sensing from space at L-band," IEEE Trans. Geosci. Remote Sens., vol. 42, no. 1, pp. 119-129, Jan. 2004.

[45] D. M. Le Vine, S. Abraham, Y. H. Kerr, W. J. Wilson, N. Skou, and S. S. Søbjærg, "Comparison of model prediction with measurements of 
galactic background noise at L-band," IEEE Trans. Geosci. Remote Sens., vol. 43, no. 9, pp. 2018-2023, Sep. 2005.

[46] J. E. Tenerelli, N. Reul, A. A. Mouche, and B. Chapron, "Earth-viewing L-band radiometer sensing of sea surface scattered celestial sky radiation-Part I: General characteristics," IEEE Trans. Geosci. Remote Sens., vol. 46, no. 3, pp. 659-674, Mar. 2008.

[47] G. A. Duck and D. E. Gary, "The sun at $1.4 \mathrm{GHz}$," Astron. Astrophys., vol. 124, no. 1, pp. 103-107, 1983.

[48] A. Camps, M. Vall-llosera, N. Duffo, M. Zapata, I. Corbella, F. Torres, and V. Barrena, "Sun effects in 2-D aperture synthesis radiometry imaging and their cancelation," IEEE Trans. Geosci. Remote Sens., vol. 42, no. 6, pp. 1161-1167, Jun. 2004.

[49] B. Picard, N. Reul, P. Waldteufel, and E. Anterrieu, "Impact of solar radiation on sea surface salinity remote sensing by spaceborne synthetic aperture imaging radiometers," in Proc. IGARSS, Anchorage, AK, 2004, pp. 1926-1929.

[50] A. Camps, M. Vall-llosera, N. Reul, F. Torres, N. Duffo, and I. Corbella, "Impact and compensation of diffuse sun scattering in 2D aperture synthesis radiometers imagery," in Proc. IGARSS, 2005, pp. 4906-4909.

[51] N. Reul, J. Tenerelli, B. Chapron, and P. Waldteufel, "Modeling sun glitter at L-band for the sea surface salinity remote sensing with SMOS," IEEE Trans. Geosci. Remote Sens., vol. 45, no. 7, pp. 2073-2087, Jul. 2007.

[52] R. K. Crane, "Propagation phenomena affecting satellite communication systems operating in the centimeter and millimeter wavelength bands," Proc. IEEE, vol. 59, no. 2, pp. 173-188, Feb. 1971.

[53] F. T. Ulaby, R. K. Moore, and A. K. Fung, Microwave Remote Sensing-Active and Passive, vol. 1 \& 3. Norwood, MA: Artech House, 1981.

[54] M. Peichl, V. Wittmann, E. Anterrieu, B. Picard, N. Skou, and S. Søbjærg, Final Report: Scientific Inputs for the SMOS Level 1 Processor Development, ESA contract 10508/02/NL/GS, 2005.

[55] A. Benoit, "Signal attenuation due to neutral oxygen and water vapor, rain and clouds," Microw. J., vol. 11, pp. 73-80, 1968.

[56] H. J. Liebe, G. A. Hufford, and M. G. Cotton, "Propagation modeling of moist air and suspended water/ice particles at frequencies below $1000 \mathrm{GHz}$," presented at the AGARD 52nd Specialists' Meeting Electromagnetic Wave Propagation Panel, Palma de Mallorca, Spain, 1993.

[57] S. H. Yueh, "Estimates of Faraday rotation with passive microwave polarimetry for microwave remote sensing of Earth surfaces," IEEE Trans. Geosci. Remote Sens., vol. 38, no. 5, pp. 2434-2438, Sep. 2000.

[58] D. M. Le Vine and S. Abraham, "The effect of the ionosphere on remote sensing of sea surface salinity from space: Absorption and emission at L band," IEEE Trans. Geosci. Remote Sens., vol. 40, no. 4, pp. 771-782, Apr. 2002.

[59] N. Floury, Estimation of Faraday Rotation From Auxiliary Data. Datasets and Algorithms Suitable for SMOS, ESA Internal Document, Issue 2.4, 2007.

[60] P. Waldteufel, J. Boutin, and Y. Kerr, "Selecting an optimal configuration for the soil moisture and ocean salinity mission," Radio Sci., vol. 38, no. 3, 8051, 2003, DOI: 10.1029/2002RS002744.

[61] D. Marquardt, "An algorithm for least-squares estimation of non-linear parameters," J. Soc. Ind. Appl. Math., vol. 11, no. 2, pp. 431-441, Jun. 1963.

[62] J. M. Dow, R. E. Neilan, and G. Gendt, "The international GPS service (IGS): Celebrating the 10th anniversary and looking to the next decade," Adv. Space Res., vol. 36, no. 3, pp. 320-326, 2005.

[63] D. Bilitza, "International reference ionosphere 2000," Radio Sci., vol. 36, no. 2, pp. 261-275, 2001.

[64] M. H. Freilich, "Validation of vector magnitude datasets: Effects of random components errors," J. Atmos. Ocean. Technol., vol. 14, no. 3, pp. 695-703, Jun. 1997.

[65] A. Stoffelen, "Toward true near-surface wind speed: Error modeling and calibration using triple collocation," J. Geophys. Res., vol. 103, no. C4, pp. 7755-7766, 1998, DOI: 10.1029/97JC03180.

[66] P. Waldteufel, J.-L. Vergely, and C. Cot, "A modified cardioid model for processing multiangular radiometric observations," IEEE Trans. Geosci. Remote Sens., vol. 42, no. 5, pp. 1059-1063, May 2004.

[67] M. Zribi, D. Hauser, M. Dechambre, and P. Fanise, "Combined airborne radio-instruments for ocean and land studies (CAROLS)," presented at the Eur. Geosciences Union, Vienna, Austria, 2007.

[68] S. Delwart, C. Bouzinac, P. Wursteisen, M. Berger, M. Drinkwater, M. Martín-Neira, and Y. H. Kerr, "SMOS validation and the CoSMOS campaigns," IEEE Trans. Geosci. Remote Sens., vol. 46, no. 3, pp. 695704, Mar. 2008.

[69] A. Papoulis, Probability, Random Variables, and Stochastic Processes. New York: McGraw-Hill, 1985.

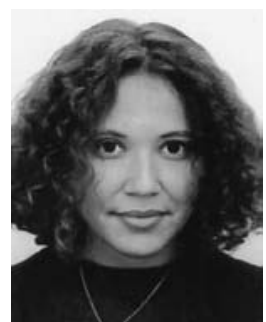

Sonia Zine received the Ph.D. degree from the University of Marne-la-Vallée, Marne-la-Vallée, France, in 2004. She has studied the potential of scatterometer and SAR data to monitor land surface parameters in semiarid areas.

Since 2005, she has been with the Laboratoire d'Océanographie et du Climat-Expérimentation et Approches Numériques (LOCEAN), Paris, France, working on the SMOS mission.

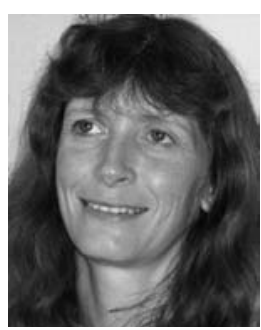

Jacqueline Boutin received the Ph.D. degree in physical methods in remote sensing from the University Paris VII, Paris, France, in 1990.

She is currently a Research Scientist at the Centre National de la Recherche Scientifique (CNRS) in the Laboratoire d'Océanographie et du Climat-Expérimentation et Approches Numériques (LOCEAN), Paris. She has widely studied the validity of remotely sensed wind speeds and the ocean/atmosphere exchange of $\mathrm{CO}_{2}$ at large scale using both satellite (wind speeds, sea surface temperature, and ocean color) and in situ data (in particular, carbon-interface ocean-atmosphere autonomous drifters, CARIOCA). Since 1999, she has been involved in the preparation of the SMOS mission. She participated in the development of an L-band sea surface emissivity model and in several airborne campaigns (WISE and Eurostarrs). She is a member of the European Space Agency Expert Support Laboratories that define and validate the processing of SMOS Level 2 measurements for the retrieval of sea surface salinity.

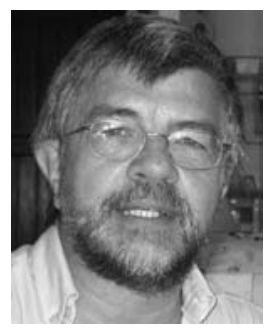

Jordi Font received the B.Sc. and Ph.D. degrees in physics from the University of Barcelona, Barcelona, Spain, in 1973 and 1986, respectively.

$\mathrm{He}$ is a Senior Researcher with the Physical Oceanography Department, Institut de Ciències del Mar, Centre Mediterrani d'Investigacions Marines i Ambientals [Spanish Research Council, Consejo Superior de Investigaciones Cientificas (CSIC)], Barcelona. He is the author or coauthor of $225 \mathrm{com}-$ munications to scientific symposia and 110 published papers. He is the Adviser of nine Ph.D. theses. $\mathrm{He}$ is a Principal Investigator in several Spanish and European research contracts. He is currently the Colead Investigator for ocean salinity in the European Space Agency SMOS mission, where he is responsible for the CSIC participation in the European Union Marine Environment and Security for the European Area operational oceanography project. Moreover, he is also the Chairman of the Physics and Climate of the Ocean Committee of the International Commission for the Scientific Exploration of the Mediterranean Sea. His main research activities include the study of marine circulation in the western Mediterranean from hydrographic, current-meter, and satellite measurements; the variability and dynamics of the ocean surface layer, and the shelf-slope exchange processes; and the use of remote sensing of the oceans in studying marine circulation and dynamics.

Dr. Font is a member of several international societies and committees and a participant in 42 oceanographic campaigns. 


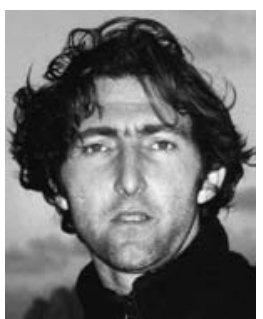

Nicolas Reul received the B.S. degree in marine science engineering from Toulon University, La Garde, France, in 1993, and the Ph.D. degree in physics (fluid mechanics) from the University of Aix-Marseille II, Marseille, France, in 1998.

From 1999 to 2001, he worked as a Postdoctoral Researcher with the Applied Marine Physics Department, Rosenstiel School of Marine and Atmospheric Science, University of Miami, Coral Gables, FL. Since 2001, he has been a Research Scientist with the Spatial Oceanography Group, Institut Français de Recherche pour l'Exploitation de la Mer, Plouzané, France, where he is responsible for the activities concerning the SMOS satellite mission. The focus of his research program is to improve the understanding of the physical processes at air-sea interface and passive/active remote sensing of the ocean surface. He has experience in applied mathematics, physical oceanography, electromagnetic wave theory, and its application to ocean remote sensing. He is currently a member of the European Space Agency/SMOS Science Advisory Group.

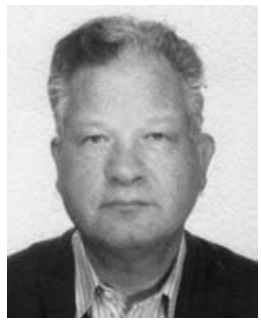

Philippe Waldteufel received the Engineering degree from the Ecole Polytechnique, Paris, France, in 1962, and the Doctorat d'Etat degree from the Université de Paris, Paris, in 1970.

He is currently a Senior Scientist with the Service d'Aéronomie du Centre National de la Recherche Scientifique, Verrières-le-Buisson, France. He has also served as the Director of the Institut de Physique du Globe de Clermont-Ferrand, the Deputy Director of the French Weather Service Research Department, and the Director for Science with the French Research Ministry. His main scientific interests include ionospheric and thermospheric physics, radar meteorology, radiowave propagation, macroeconomics, and microwave radiometry.

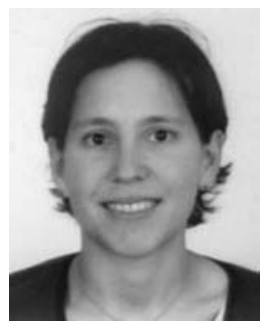

Carolina Gabarró was born in Barcelona, Spain, in 1974. She received the Telecommunications Engineering and Ph.D. degrees from the Universitat Politècnica de Catalunya, Barcelona, in 1998 and 2004, respectively.

From 1997 to 1999, she was with the European Space Research and Technology Centre, European Space Agency, Noordwijk, The Netherlands, working on ocean color remote sensing (ENVISAT mission). Since 2000, she has been with the Institut de Ciències del Mar, Centre Mediterrani d'Investigacions Marines i Ambientals-Consejo Superior de Investigaciones Cientificas, Barcelona, working on the SMOS mission. Her research interest is microwave remote sensing.

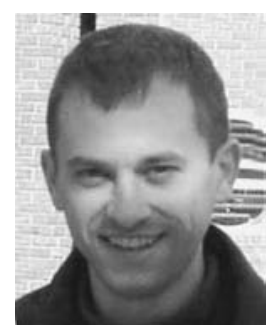

Joseph Tenerelli received the B.S. degree in atmospheric sciences from the University of Washington, Seattle, in 1994.

From 1999 to 2005, he was a Research Associate with the Rosenstiel School of Marine and Atmospheric Science, University of Miami, Miami, FL, where he was part of a team that developed a coupled atmosphere-ocean-surface-wave version of an atmospheric mesoscale model (MM5) with vortexfollowing mesh refinement suitable for simulating hurricanes. Since April 2005, he has been a Research Engineer with the Institut Français de Recherche pour l'Exploitation de la Mer, Plouzané, France, working as part of a team developing an algorithm to retrieve sea surface salinity from L-band radiometric measurements (the European Space Agency's SMOS project).

François Petitcolin, photograph and biography not available at the time of publication.

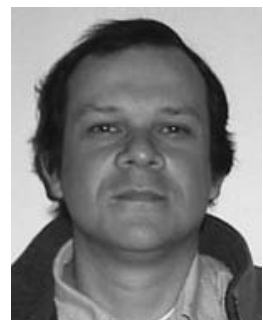

Jean-Luc Vergely received the Engineering degree from the Ecole Nationale du Génie des Eaux et de l'Environnement de Strasbourg, Strasbourg, France, in 1988, and the Ph.D. degree in statistics applied to astronomy from Louis Pasteur University, Strasbourg, in 1998.

He has managed cooperative projects in Africa. He is currently with ACRI-ST, Sophia Antipolis, France.

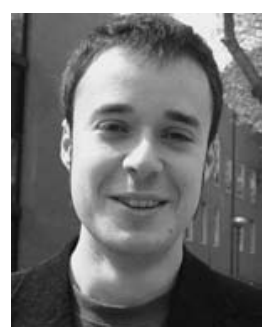

Marco Talone was born in Valmontone, Italy, in 1981. He received the B.S. and M.S. degrees in telecommunication engineering from the Tor Vergata University, Rome, Italy, in 2003 and 2006, respectively. In 2005, he worked on his M.S. thesis in the Department of Signal Theory and Communications (TSC), Polytechnic University of Catalonia, Barcelona, Spain. In 2006, he joined the TSC Group as a Ph.D. student.

$\mathrm{He}$ is currently with the Institut de Ciències del Mar, Centre Mediterrani d'Investigacions Marines i Ambientals-Consejo Superior de Investigaciones Cientificas, Barcelona. His research interests deal with microwave radiometry and sea surface salinity retrieval methods.

Steven Delwart, photograph and biography not available at the time of publication. 